\section{ZONAS DE RESERVA CAMPESINA EN EL PROCESO DE PAZ, UNA LUCHA POR LA EFECTIVIDAD DE LOS DERECHOS CAMPESINOS EN COLOMBIA, LA EXPERIENCIA DEL SUMAPAZ *}

\author{
THE AREAS OF PEASANT RESERVES IN THE \\ PEACE PROCESS, A STRUGGLE FOR THE \\ FULFILMENT OF THE RIGHTS OF PEASANTS \\ IN COLOMBIA, THE SUMAPAZ EXPERIENCE
}

\author{
ZONAS DE RESERVA CAMPONÊS NO PROCESSO \\ DE PAZ, UMA LUTA PELA EFICÁCIA DOS \\ DIREITOS DOS CAMPONESES NA COLÔMBIA, A \\ EXPERIÊNCIA DE SUMAPAZ
}

\author{
Myriam Sepúlveda López ${ }^{a}$ \\ myriam.sepulveda@unicolmayor.edu.co \\ Jorge Ivan Sotelo Gaviria \\ jsoteg@hotmail.com \\ Fecha de recepción: 25 de octubre de 2016 \\ Fecha de revisión: 05 de diciembre de 2016 \\ Fecha de aceptación: 22 de mayo de 2017
}

\title{
RESUMEN
}

A través de este artículo, se describe y evalúa la efectividad de la figura de Zonas de Reserva Campesina (ZRC), como instrumentos de desarrollo y ordenamiento social, ambiental y territorial, desde el nivel institucional, normativo e histórico, así como su relación con los procesos agrarios campesinos, con el objetivo de evaluar si su proceso de constitución es efectivo, en cumplimiento de garantías constitucionales y legales establecidas, como respuesta dentro un nuevo paradigma de posconflicto con un enfoque de derechos hacia lo rural.

De manera coyuntural, se relacionan las Zonas de Reserva Campesina (ZRC) investigado en el marco del proceso de paz, en la búsqueda de soluciones sociales a nivel rural en el conflicto armado colombiano, como mecanismo facilitador para la construcción de la paz.

\footnotetext{
* Artículo de investigación científica y tecnológica. Producto de investigación de monografía socio jurídica aprobada Laureada, para optar por el título de abogado, de la Facultad de Derecho en la Universidad Colegio Mayor de Cundinamarca.

a. Doctora en Filosofía Jurídica de la Universidad Nacional de Educación a Distancia de Madrid, España, magister en Derecho Administrativo de la Universidad Libre, magister en Educación con énfasis en investigación de la Universidad Pedagógica Nacional de Colombia, especialista en Instituciones Jurídico Familiares de Universidad Nacional, especialista en Docencia Universitaria de la Universidad Santo Tomás, Trabajadora Social de la Universidad Colegio Mayor de Cundinamarca, Abogada de la Universidad La Gran Colombia. Decana de la facultad de derecho de la Universidad Colegio Mayor de Cundinamarca.
}

b. Abogado, Egresado de la Universidad Colegio Mayor de Cundinamarca

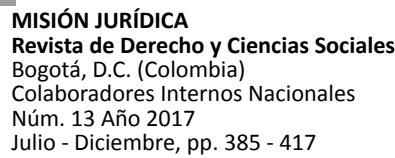


Para poder realizar la evaluación, se tomó como ejemplo el proceso social y jurídico de la formación y constitución de una nueva ZRC en la región del Sumapaz, desde una perspectiva descriptiva y etnográfica. Se analiza el proceso para la comunidad, así como el impacto social, económico y ambiental para la región de un instrumento para mejorar la calidad de vida de los campesinos.

\section{PALABRAS CLAVE}

Campesino, Derechos Humanos, Efectividad, Evaluación, Paramo, Proceso de Paz, Reforma Agraria, Reforma Rural Integral, Sumapaz, Zonas de Reserva Campesina.

\section{ABSTRACT}

Through this research is described, and evaluated the effectiveness of the figure of Peasant Reserve Areas as tools for development and social, environmental and land management, from the institutional, legal and historical level and their relationship with the agrarian processes of peasants. The aim of the study is to evaluate the process of creation of a Peasant Reserve Zone to find if this is effective, in accordance with constitutional and legal guarantees established in response with a new paradigm of post-conflict social issues with a focus on rights of rural areas.

In the juncture, it relates the importance of Peasant Reserve Areas investigated in the framework of the peace process in the search of social solutions in rural areas, scenarios of the Colombian armed conflict, as a facilitating mechanism for peace building.

To perform the evaluation, it was taken as example the social and legal process of the formation of a new peasant reserve zone in the region of Sumapaz, from a descriptive and ethnographic perspective. The process for the community is analyzed, as well as the social, economical and environmental impacts for the region of a tool to improve the life quality of peasants.

\section{KEY WORDS}

Farmer, Human Rights, rural development, principle of Effectiveness of Rights, evaluation, social struggle, moorland, public politics, peace process, agrarian reform, comprehensive rural reform, subject of rights, Sumapaz, peasant reserve zones.

\section{RESUMO}

Através deste artigo, que descreve e avalia a eficácia da figura de Zonas de Reserva Campesina (ZRC), como instrumentos de desenvolvimento e gestão social, ambiental e territorial, a nível institucional, normativa e históricos, bem como sua relação com processos agrícolas de camponês, a fim de avaliar se o seu processo de Constituição é eficaz, nos termos constitucionais e legais garantias prestadas, como resposta dentro de um novo paradigma de pós-conflito, com uma abordagem de direitos para o rural.

As ZRC são investigadas no âmbito do processo de paz na busca de soluções sociais a nível rural no conflito armado colombiano, como mecanismo facilitador para a construção da paz.

Para realizar a avaliação, o processo social e jurídico da formação e constituição de um novo ZRC na região de Sumapaz foi tomado como exemplo, de uma perspectiva descritiva e etnográfica. 0 processo para a comunidade é analisado, bem como o impacto social, econômico e ambiental para a região de um instrumento para melhorar a qualidade de vida dos camponeses.

\section{PALAVRAS-CHAVE}

Camponês, Direitos Humanos, Desenvolvimento Rural, Luta Social, Páramo, Processo de Paz, Reforma Agrária, Reforma Rural Integral, Sumapaz, Zonas de Reserva Camponês.

\section{INTRODUCCIÓN}

El presente artículo, gira en torno al estudio académico del proceso de constitución de una Zona de Reserva Campesina (ZRC), para la región del Sumapaz, mediante el cual, la población campesina busca en el ejercicio de sus derechos, desarrollar aspectos como la movilización social y reivindicación histórica y su vez mejorar sus condiciones de calidad de vida.

El propósito y objeto del estudio consiste en poder evaluar el proceso de constitución de una Zona de Reserva Campesina de Sumapaz (ZRC) para encontrar si este es efectivo, en cumplimiento de garantías constitucionales y legales establecidas, como respuesta dentro un nuevo paradigma del posconflicto con un enfoque de derechos que vuelven a mirar y reconocer la importancia de lo rural. 
Es clave resaltar el momento coyuntural del país dentro del proceso de paz, que busca solucionar el conflicto armado y a su vez plantear alternativas para los problemas estructurales de la violencia en Colombia a nivel rural. Haciendo especial énfasis en las ZRC, como mecanismo facilitador para la construcción de la paz.

Esto parte, de describir el proceso histórico, político social, administrativo y jurídico del proceso de constitución de la ZRC, teniendo en cuenta el papel institucional que se viene desarrollando en la región, el cual podría llegar a tener gran impacto en las condiciones de sus habitantes.

A su vez, se describen los procesos históricos de organización y movilización social de la región, su relación con la institucionalidad pública y el entorno jurídico que ha enmarcado el proceso de constitución de la reserva campesina. Seguido a esto, se identificó y describió ese proceso demográfico y geográfico de la comunidad del Sumapaz, el recorrido histórico de la población, los sucesos relevantes y el proceso organizativo y asociativo de los campesinos pretendientes de la constitución de ZRC para la comunidad.

En un principio se identificó y analizó el devenir histórico del campo colombiano, la dinámica de la tierra y los problemas agrarios suscitados por fallas institucionales y legislativas, que repercutieron en la vulneración a los derechos a campesinos y en la manifestación de movilizaciones campesinas.

Posteriormente, se recopilan y describen aspectos normativos aplicables tanto a la figura de las ZRC, como a la regulación, protección, garantía de los derechos a campesinos y la legitimación social y política de la movilización social, específicamente, aquellas normas aplicables desde el ámbito jurídico empezando por el nivel constitucional, internacional, legal y jurisprudencial sobre la figura de las ZRC, que inciden en la efectividad del proceso, precisando las fases y etapas del proceso de constitución.

Para poder lograr de manera confiable y válida la investigación con enfoque cualitativo, el cual buscó describir las características de la región del Sumapaz y sus habitantes, con un método deductivo, de corte socio jurídico, orientada con el tipo de investigación descriptiva a partir de lo histórico, evaluativa desde lo jurídico e institucional, y etnográfica desde lo social, que permita dar cuenta de las condiciones de la comunidad que busca constituir la ZRC. Se usaron técnicas de recolección de información en campo visitas programadas y la observación etnográfica y participativa, con el fin de describir eventos del fenómeno campesino, organizativo y político de la comunidad en búsqueda de reconocimiento. Con las visitas al territorio, se aporta la evidencia tomada en un informe de diario de campo como instrumento para la recolección y captura de información.

Lo anterior, se centró en evaluar el impacto a través de la constitución de una ZRC nueva, sobre los derechos de los campesinos, las actividades de las comunidades, sus necesidades y sobre la dinámica territorial por medio de la gestión pública institucional en el ámbito jurídico administrativo y socio político, no solo como el Estado garantista y mediador, sino como fuente de obligaciones constitucionales, que buscan la efectividad y la consecución de los derechos y bienestar de la sociedad campesina.

\section{METODOLOGÍA}

Para la investigación que precede este artículo, parte metodológicamente desde un enfoque cualitativo, buscando describir las características y condiciones del proceso históricas, sociales de la población de la localidad del Sumapaz, respecto al proceso de constitución de la ZRC. Sustentada de la consulta de fuentes documentales y teóricas, para logar describir de forma general del hechos históricos que tuvieron influencia, eventos políticos que marcaron la dinámica social campesina, referentes legislativo y normativos reseña sobre los procesos del Sumapaz, buscando la conexión del proceso de constitución de Zonas de Reserva Campesina y las conclusiones del caso sumapaceño, a partir del método deductivo, como enfoque de razonamiento, en el cual se desciende desde lo general, con la preguntas, ¿que son las Zonas de Reserva Campesina?, ¿cuáles son las características del fenómeno campesino y el problema agrario colombiano?, y, posteriormente, lo particular hacia el caso de una ZRC para el Sumapaz, tomando como base el contexto socio político en el territorio rural.

En primer lugar, la forma de la investigación utilizada, es teórico práctica, de corte socio jurídica, clasificación de Jaramillo (1999), complementada con el tipo de investigación descriptiva de acuerdo a Sabino (2000). En segundo lugar, al referirse 
al objetivo de evaluar la efectividad del proceso de constitución de la ZRC para el Sumapaz de acuerdo a la definición de Sandin (2003) se desarrolla la noción de evaluación de (ICFES, 2002) la metodología evaluativa y otros aspectos conceptuales como: institución, programa, evaluación e investigación evaluativa para determinar sus alcances dentro del caso de estudio.

Luego, mediante el método etnográfico, se realizó el acercamiento al Sumapaz y a sus habitantes, para conocer e interactuar mediante una observación directa las actividades relacionadas con las formación de una ZRC, para la perspectiva y visión campesina propia sobre el proceso.

\section{RESULTADOS}

\subsection{Sumapaz}

Esta zona se encuentra ubicada en el sur de la ciudad de Bogotá D.C, corresponde a la localidad número 20 de la ciudad, establecida como la localidad más extensa del distrito. Posee un ambiente diferente al paisaje urbano, netamente rural, pueden pasar horas sin verse a una persona en el camino o kilómetros donde lo único que se aprecia es un majestuoso ambiente natural de verdes y azules, entre montañas y el cielo. Características trascendentales para comunidad local al tener, cuidar y preservar una fuente única de recursos naturales. La zona se caracteriza por ser montañosa y de extensos valles, una de las fuentes hídricas más grandes de Colombia que alimenta a los ríos Magdalena y Orinoco, su clima es lo suficientemente frio como para albergar la mayor extensión de páramo en el mundo.

Cuenta con cerca de las 2.531,82 hectáreas que corresponden al $33 \%$ de la localidad, aproximadamente el $15.8 \%$ del área total del Distrito Capital y el 21\% del área rural de Bogotá, esta comprende las 14 veredas del corregimiento de San Juan, ubicado al sur de la localidad en la cuenca del río Sumapaz y las veredas de Ánimas y Sopas del corregimiento de Nazareth, ambos corregimientos pertenecientes a la localidad de Sumapaz.

\subsection{Antecedentes históricos de la región del Sumapaz}

A mediados del siglo XIX, época en la que empezó en la región el proceso de colonización del Sumapaz, momento donde el páramo era reconocido como un lugar desolado, un corredor que tendría un papel decisivo en las movilizaciones colonas campesinas hacia el oriente del país.

Con el reconocimiento del Decreto Nacional 489 del 7 de noviembre de 1895 y la Ley 162 de 1896, surgieron conflictos entre terratenientes, colonos y arrendatarios, quienes cuestionaron los patrones tradicionales de tenencia y explotación de tierras y generaron sucesivos enfrentamientos, que se tornaron en recurrentes de invasiones y desalojos dentro de la Hacienda Sumapaz. Esta etapa de luchas, conflictos, triunfos y retrocesos para la población, como rezago colonial, disputas entre colonos $y$ arrendatarios, asentamientos latifundios en tierras baldías y tierras realengas para la explotación de maderas, dio origen gran parte de los conflictos agrarios y de tenencia de la tierra.

Paralelamente a los conflictos agrarios nacionales, se conformó la Sociedad Agrícola de la Colonia de Sumapaz asociada al Partido Comunista en 1928, bajo la dirección de Erasmo Valencia, quien más tarde fundaría el Partido Agrario Nacional (PAN) en 1930, con el fin de dotar a los campesinos de una capacidad organizativa y participativa propia en las corporaciones de elección popular.

Debido a los conflictos de la tierra y los procesos de movilización campesina producidos en los años veinte y treinta, suscitado por el sistema latifundista de explotación agraria y la falta de reforma, conllevo al levantamiento de la población colona del Alto del Sumapaz, específicamente del corregimiento de San Juan, con lo cual surge el Movimiento Agrario del Sumapaz en el año de 1924, liderado por Erasmo Valencia y Juan de la Cruz Varela, lo que obligó a la primera intervención estatal en la región que llevó a la creación de La Colonia Agrícola del Alto del Sumapaz, (también denominado Movimiento Agrario del Alto del Sumapaz) que mediante el Decreto 1110 de 1928 que reguló lo concerniente a la adjudicación de baldíos para colonias agrícolas establecido en la Ley 114 de 1922.

En un comienzo, la movilización campesina tuvo como objetivo, el problema de la tenencia y ocupación de la tierra, con el modelo latifundista hasta este punto que predominaba en general en el Sumapaz. Luego del resurgimiento de la violencia en la década de 1940, muchos colonos 
de Sumapaz habían logrado reconocimiento de la posesión de sus tierras por vía de adjudicación de baldíos y la parcelación de varias haciendas, En este periodo se avanzó en el reconocimiento jurídico de los procesos de movilización campesina y de las problemáticas reivindicadas, descrito por (Cadavid, 2014) dentro del proceso de democratización del territorio.

El periodo de "la Violencia" desencadenada en los años 50's y sobre las posibilidades de equilibrar la distribución inequitativa de la tierra de lo cual también surge el despliegue de represión armada anticomunista, que inicia con el asesinato de Jorge Eliécer Gaitán a lo que Sánchez (1985) llamo la tercera fase, caracterizado en la resistencia armada hacia los años $60^{\prime}$ con las denominaciones de los rebeldes a bandidos y de la conformación de agrupaciones en lo denominado la provincia del Sumapaz.

De esa manera, esa llamada tercera fase de la violencia rural colombiana, la violencia política vivida en todo el país en los años 50's, época en la que se constituyeron grupos armados insurgentes, incentivados en la represión política del Gobierno, algunos campesinos de la región del Sumapaz y del Tequendama decidieron continuar con la lucha y se desplazaron hacia el año 1956, a la región de Guayabero, donde se unieron a las guerrillas del sur del Tolima, según lo describe Londoño, (2011, p. 741). Situación que, se agudizo con la expedición de la Ley 135 de 1961, que pretendía reformar la estructura social agraria en contra de la concentración, al dotar de tierra a quienes no la poseían, fortalecer la explotación económica equitativa y la distribución ordenada y racional de la tierra. Ley que creo el Instituto Colombiano de Reforma Agraria - INCORA.

Sin embargo, en la aplicación de las medidas de reforma y a pesar de que esta disposición legal diseñó estrategias y herramientas financieras y jurídicas para facilitar el acceso a la propiedad de la tierra a los campesinos, no significó necesariamente mejores condiciones de vida para los campesinos del Sumapaz. Fue así que, desde la década de 1960, la organización campesina en el alto de Sumapaz se fortaleció de manera importante y se enfocó en la consecución de condiciones dignas para la permanencia en el territorio, con lo que el Movimiento Campesino fortificó su alianza y apoyo al Partido Comunista Colombiano (PCC) lo cual relata Marulanda (1990) que esto genero por parte de grandes propietarios de la región apoyados por gobierno en acciones de represión, amenazas y asesinatos selectivos.

La respuesta de la comunidad campesina del Sumapaz y Oriente del Tolima, fue de manera armada por parte de los campesinos y justifico así, en lo que Tirado (1989) denomino el Nuevo Orden Revolucionario y llevo la violencia de la protesta social liberal a las zonas rurales y poblaciones veredales y tras otra ola de represión militar por parte del gobierno, generaría nuevas condiciones para la apropiación indebida de terrenos y la reconcentración de la propiedad en el Sumapaz como a través del desplazamiento forzado que Cadavid (2014) citando a Varela y Romero (2007) señala que los campesinos de la región, continuo hasta entrados los años 90's cuya oposición campesina paso de acciones de Resistencia Civil como alternativa desarrollada por (Prada, 2011) a la Resistencia Armada de (Tirado, 1989) y engendraría desde la mañana de 9 de Abril de 1948 la violencia que duraría en el país hasta hoy día.

Posteriormente, la movilización campesina, se consolidaría en el Sindicato de Trabajadores Agrícolas del Sumapaz - SINTRAPAZ, el cual agremió a más de la cuarta parte de la población, orientado a la defensa del territorio rural de las comunidades campesinas del alto de Sumapaz y por ello, uno de sus objetivos más importantes fue la exigencia de respeto por los derechos humanos, lo cual, a su vez, se enmarca en una línea estratégica de solución política del conflicto descrito por el trabajo de Campo de (Cadavid, 2014).

Es así que, la lucha campesina en la región del Sumapaz es una historia de transformaciones agrarias, de organizaciones base articuladas y fortalecidas, que con el tiempo, el factor Tierra que ha sido principalmente el objeto de la lucha, convierte de un sujeto político colectivo a sujeto de derechos individualmente al campesino. Por tal motivo, la movilización social y campesina en la región del Sumapaz trabaja en pro del desarrollo local fortaleciéndose a través de organizaciones como SINTRAPAZ, las iniciativas locales y articulándolas con las políticas públicas.

\subsection{El páramo y la ZRC}

Para reconocer la importancia de la experiencia de constitución de una (ZRC) en el 
Sumapaz, es necesario reconocer la importancia ecológica y ambiental del territorio por lo que, al destacar y describir las características geográficas y las condiciones actuales de la región como lo es el páramo del Sumapaz, el Parque Nacional Natural, que hoy día se encuentran de manera crucial resguardado en las medidas de protección ambiental.

Es así como, se encuentran los ecosistemas de la localidad, parte importante del recurso hídrico mundial, en lo que refiere a las cuencas y nacimientos de ríos; Magdalena y Orinoco, también como abastecedor principal de agua para Bogotá. Tal como se describe en el estudio de la (Alcaldía Bogotá, 2004).

Por esas razones, que se declaró una porción del territorio de la localidad, Parque Nacional Natural (PNN) en el año de 1977 mediante la Resolución 153 del en su momento Instituto Nacional de los Recursos Naturales Renovables y del Ambiente (INDERENA), que comprende aproximadamente el $43 \%$ del total del área de la región y el complejo de páramos más grande del mundo, el cual según datos del Von Humboldt (2012), tiene una extensión total de 333.420 $\mathrm{Ha}$, de las cuales solo 142.112 Ha se encuentran protegidas bajo la figura protegida por el Parque Nacional Natural.

En pocas palabras, el PNN Sumapaz, es uno de los lugares más biodiversos en géneros y especies de flora colombiana, posee un gran número de organismos, muchos de ellos endémicos que hacen del Parque un reservorio importante de diversidad biológica, ecológica y genética, compuesto por el páramo Cruz verde Sumapaz. Adicionalmente es regulador hídrico de 3 regiones hidrográficas como el Rio Meta, Magdalena y Guaviare, como parte integral del PNN del Sumapaz.

No obstante, las locomotoras minero energéticas, iniciativa de empresas como EMGESA, para la construcción de megaproyectos hídricos, en el macizo del Sumapaz, al sur de Bogotá, pues en total oposición está la comunidad, la cual a través de líderes, juntas comunales, organizaciones base, ambientales y juveniles con movilización social, realizada el día 9 de agosto de 2015, en la vereda Bajo Ariari del municipio de Cabrera, Cundinamarca, para la defensa del territorio y la conservación de la fuentes hídricas, que amenaza los recursos de la localidad y su calidad de vida en donde la comunidad sumapaceña rechaza la implementación de los megaproyectos (represa, hidroeléctrica, minería, hidrocarburos y plantaciones industriales) invocando el derecho al agua, la vida y la pervivencia en el territorio para evitar la contaminación de las fuentes hídricas.

No solo el perjuicio ambiental que se generaría, también está la afectación a aquellas familias que siendo poseedoras de terrenos sin título, se encuentran en la informalidad de la propiedad y que se verían desplazadas sin opción de reparo. Por lo que se planteó el fortalecimiento de la soberanía y autonomía sobre el buen uso del agua como bien común, protegiendo los nacimientos y rondas hídricas, mejorando el proceso de acueductos comunitarios veredales y la construcción de nuevos acueductos, con distritos de riego administrados por la organización comunitaria garantizando el agua potable y la estrategia del manejo de aguas residuales en el marco de tecnologías ecológicas alternativas a través del Plan Ambiental de la Localidad PAL (Alcaldía Bogotá, 2012). Elemento que se fortalecería con la constitución de las (ZRC) y del Plan de Desarrollo Sostenible (PDS), para la región como instrumento de planificación ambiental campesino.

Es por esto, que la (ZRC) se implementa como una herramienta de apropiación y defensa del territorio, que se formaliza a través del (PDS) y se desarrolla de manera participativa donde se incluyen normas que regulan la conservación, protección y utilización de los recursos naturales bajo el criterio de desarrollo sostenible para actividades de productivas y uso del suelo. Este plan expone los riesgos socio ambiental generado por actividades minero energéticas, el rechazo a los proyectos neoliberales y las posibles consecuencias ambientales, mediante el no acuerdo de condiciones y acercamiento para la entrada de la empresa a la región. (Asosumapaz, 2013). A lo que la comunidad propone Prácticas culturales de conservación ambiental en la población a través de las cuales ya se ha ido mejorando el manejo de los recursos naturales como el agua y bosques.

“El agua no se vende! proclamación local argumentado "La comunidad NO considera la posibilidad de inserción al mercado de servicios ambientales, como fuente de ingresos, no 
comercializable" PDS 27 agosto de Diario de Campo. (2016)

Es por eso que en la audiencia de socialización de PDS del 27 de Agosto de 2016, los voceros de la comunidad expusieron su negativa a las modalidades pago por servicios ambientales, pues ven en esto la forma de comercializar los recursos, pues no es un esquema dinámico para el beneficio social, sino que propone iniciativas de conservación como medio para hacer del agua una mercancía.

\subsection{Los campesinos del Sumapaz}

¡Esta es otra Bogotá!, así podría describirse al Sumapaz, con lo encontrado en el trabajo de campo, al describir la región y sus habitantes, una región, fuera del ruido, contaminación y velocidad de la urbe, característica con alto significado social, pues la calidad de vida contado por sus habitantes, gira entorno a la paz que se siente al habitar la zona, pues al entrar en contacto con la tierra y percibir el sustento de la misma, se encuentra la armonía de vida, que atrae a sus habitantes.

Es un lugar lleno de, áreas verdes, espacios naturales puros, sin la contaminación de la ciudad, el Sumapaz es la idea originaria de un entorno inexplorado, donde la mano del hombre no ha tenido los mismos efectos. Su baja densidad poblacional, su vocación agropecuaria de baja escala, ha permitido que el lugar, represente un sentido de conservación y preservación natural como fuente, de riqueza hídrica y biológica.

Esta armonía y adaptación al entorno, lleva al fuerte arraigo de los campesinos con el páramo, con la tierra, arraigo cultural que lleva varias décadas, a través de varias generaciones familiar asentadas en la región. Históricamente, el Sumapaz tiene importancia y participación política descrita en los recorridos políticos del conflicto en Colombia, especialmente en el centro del país, dando a esta población campesina, posturas consolidadas ideológicamente en la defensa del territorio.

Esta defensa social campesina, se sustenta en un modelo de desarrollo auto sostenible, basado en la seguridad y soberanía alimentaria, pues mientras que el $22,2 \%$ de la población padece la inseguridad alimentaria, es decir tienen incertidumbre sobre la disponibilidad diaria de alimentos en el hogar, pues como lo identifica (ILSA, 2013) los sistemas productivos y de comercialización para la zona son deficientes e insuficientes. Caracterizado por falta de ingresos, o ingresos muy bajos y hábitos alimenticios poco saludables dentro de la población.

Ilustración. Mural San juan, Soberanía alimentaria

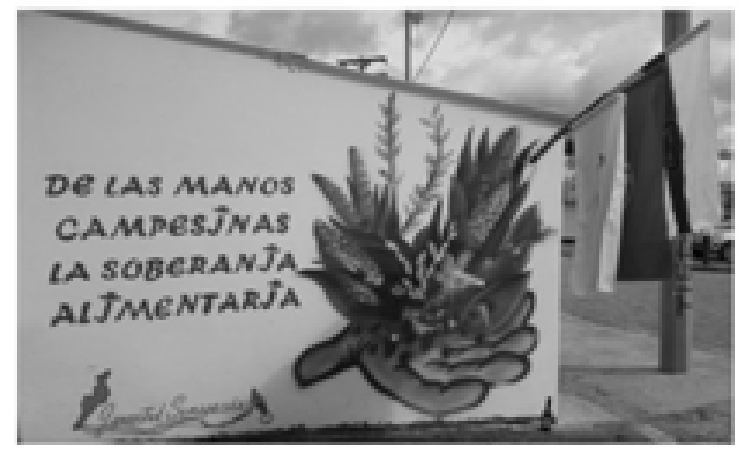

Fuente: informe de Diario de Campo 2016

Es a través de murales como el ubicado en la vereda de San Juan, que la comunidad expresa las intenciones productivas, para sí mismos, como para la comercialización masiva, sirviendo de proveedor directo de alimentos cosechas allí, para el distrito capital.

Concluyendo esta parte, fue la misma comunidad a través de los estudios del Plan de Desarrollo sostenible PDS, que definió las dimensiones del desarrollo local del Sumapaz a nivel Ambiental, social, económica, institucional), analizó la viabilidad y conveniencia general para la implementación de la figura de reforma agraria de (ZRC) en la Localidad, análisis de lo que serían las principales recomendaciones en términos de objetivos, ejes de intervención y estrategias para su desarrollo.

\subsection{Estado del proceso de Constitución de la (ZRC) del Sumapaz}

La experiencia del Sumapaz, con la constitución de una (ZRC) en la localidad, parece una histórica de nunca acabar, pues pese a las gestiones y los esfuerzos de la comunidad por reunir y cumplir con los requisitos exigidos administrativamente, luego de más de 5 años en proceso formal, no se 
vislumbraba éxito sobre reconocimiento legal a la solicitud de constitución.

Actualmente, el trámite de constitución de la (ZRC), tiene origen en la comunidad, representada por SINTRAPAZ, que mediante la Resolución 3180 del 25 de noviembre de 2011, de la Gerencia General del INCODER dio inicio al trámite administrativo para seleccionar, delimitar y constituir una (ZRC) del Sumapaz, bajo los objetivos, procedimientos, criterios orientadores y componentes establecidos en la Ley 160 de 1994, el Decreto 1777 de 1996 y el Acuerdo 024 de 1996 más adelante descritos.

Luego de esto, el proceso se detuvo en la etapa de socialización de propuesta de Plan de Desarrollo Sostenible - PDS, para la Zona, desde el mes de agosto del año 2013, pese a que acorde a lo previsto en el acuerdo 024 artículo 8, y hasta que el primer semestre de 2016, a través de una convocatoria pública a las entidades integrantes del Sistema Nacional de Reforma Agraria y Desarrollo Rural, del Sistema Nacional Ambiental y demás organismos públicos y privados, con el fin de promover la concertación interinstitucional, para el diseño, financiamiento y armonía del PDS, así como los planos cartográficos y buscar las alianzas público privadas con los intereses sociales y los requerimientos técnicos y jurídicos.

\section{La constitución de una (ZRC), por vías de hecho.}

A causa de la prolongación indefinida del proceso de constitución, fue la comunidad, haciendo valer sus pretensiones de una (ZRC), como manifestación soberana se auto declaro una (ZRC), de forma pacífica y democrática mediante asamblea de SINTRAPAZ, el 13 de febrero del año 2015, realizada en el corregimiento de San Juan, bajo el postulado que las Zonas son territorio de paz, soportados en la autonomía campesina y territorial. Luego de esperar que las gestiones administrativas y políticas del INCODER, postergadas indefinidamente por parte del gobierno nacional, decisiones que a falta de mejor razón, no tienen justificación, la comunidad en asamblea de SINTRAPAZ, acompañada de ANZORC, debatió el tiempo de dilatación y suspensión indefinida del proceso, desde cuando el INCODER debió haber desarrollado la audiencia pública de constitución en el Sumapaz había adelantado.
En consecuencia la auto proclamación de una (ZRC) de hecho, pese a estar por fuera del ordenamiento jurídico, y no tener validez ante terceros de manera oficial, pero marca un precedente de legitimización popular, pues la falta de respuesta institucional, solo debilita la confianza y credibilidad en las personas que deberían verse beneficiadas y cobijadas con la gestión pública a realizar con la figura. Siendo el Sumapaz no la primera en hacerlo.

Es ahí, donde el principio de efectividad de los derecho, mediante la inefectividad administrativa toma relevancia y contexto, pues el exponer a una comunidad que como se describe, sufre por circunstancias sociales, políticas y económicas antepuestas, así se ve desplegada a actuar en contra de las mismas autoridades y hasta de la misma norma, evento que deslegitima tanto la gestión pública, tanto como a la norma misma, al no lograr exitosamente llegar a sus objetivos y obligaciones.

Ulteriormente, se logró la realización de la convocatoria y celebración Audiencia pública pendiente, que fue llevada a cabo el 27 de agosto de 2016, debido al cambio institucional en el tema de tierras, con la liquidación del INCODER y la entrada de la Agencia Nacional de Tierras - ANT, entidad nueva, esta última, bajo la premisa de los compromisos agrarios pactados en el proceso de negociación de la Habana, lo que volvía a poner a las (ZRC) en el juego, luego de 14 años de suspensión y falta de gestión administrativa para continuar con el procedimiento, no solo de esta (ZRC) sino de la otras presentadas.

Como resultado de la convocatoria realizada se tuvo la participación de gran cantidad de instituciones públicas, algunas de las cuales realizaron su intervención con relación a la (ZRC), esta audiencia consistió en, la exposición técnica del PDS por parte de SINTRAPAZ, para revisar de la propuesta de constitución y solicitar los ajustes del PDS y de actualizar y precisar datos $\mathrm{y}$ aspectos sobre los cuales, se recomendaron durante la audiencia, por parte de los diferentes interventores y participantes, acuerdos que se plasmaron unos compromisos faltantes para la culminación del procedimiento.

Finalmente, la constitución de las zonas podría someterse a lo que pase en el proceso paz, condicionamiento que hoy parece estar en vilo, pues las propuestas realizadas, son el objeto de la 
renegociación, del marco para la paz. Sobre todo la actitud institucional respecto a la viabilidad de constitución y reactivación de la figura, tal como lo expreso el delegado de la agencia durante el evento, pues esta actitud fue bien recibida por la comunidad durante el transcurso de la audiencia $\mathrm{y}$ al final del acuerdo pactada.

Frente a los compromisos las organizaciones campesinas locales, apoyadas por ANZORC, decidieron iniciar actividades, para la actualización, ajustes del PDS, actualización de información, atención de observaciones y diálogo y concertación de actividades con las instituciones relacionadas, iniciando con el grupo de trabajo de acceso a tierras, de la Agencia Nacional de Tierras. El ideal es poder cumplir con los requerimientos, lo antes posible, con el fin de dar continuidad al trámite, aprovechando la reactivación bajo los postulados del proceso de paz y las modificaciones institucionales.

\subsection{Las expectativas de las (ZRC) en el proceso de paz.}

Actualmente en Colombia, se vive un momento coyuntural e histórico, en el marco de las negociaciones para la terminación del conflicto armado interno entre el grupo guerrillero de Fuerza armada Revolucionarias de Colombia FARC y el gobierno nacional, oportunidad en la cual se busca poder comenzar una fase de construcción de paz, mediante un negociación que converjan en las causas estructurales e históricas del conflicto especialmente en el campo, a través de las salidas concertadas a la violencia y cese al fuego principalmente.

En las negociaciones para la paz, se generaron unas expectativas, que sin importar el resultado plebiscitario, engendraron en la población una alternativa al fin del conflicto y la necesidad de llegar de mejorar la condiciones de vida de los nacionales a través del dialogo, en especial en las zonas rurales, donde la población es campesina, que ha sufrido el conflicto de cerca, siendo actor, víctima y publico a la vez, durante mucho más de 60 años.

Como elemento importante, que se destacó en el trabajo de campo, fue la actitud la comunidad campesina relacionada a la constitución de la (ZRC), pues en lo expuesto durante la audiencia pública del 27 de agosto, se mostró una visión positiva, frente a la posibilidad de la reactivación de la figura, como mecanismo para a su vez reactivar el campo en Colombia.

"Cabe anotar que la audiencia fue anterior a las votaciones del plebiscito del 26 de septiembre de 2016"

Como se afirmó arriba, los campesinos del Sumapaz, ven con buenos ojos, pues, las posibilidades de la (ZRC) están vivas de nuevo, posibilidades para la población se abren con la mesa de negociaciones que se dio en la Habana, pues parte del primer punto del documento final, versa de una política de Desarrollo Agrario Integral.

Es por eso, que en el ejercicio de derechos que desarrollan las organizaciones y asociaciones campesinas alrededor de las zonas de reserva campesina, van de la mano con la iniciativas de paz, propuestas en el acuerdo final, pues como lo refiere el documento oficial, en el punto primero. Hacia un Nuevo Campo Colombiano: Reforma Rural Integral:

Que a la transformación estructural del campo y en particular al cierre de la frontera agrícola, contribuyen los campesinos, las campesinas y las comunidades indígenas, negras, afrodescendientes, raizales y palenqueras y demás comunidades étnicas en sus territorios, con un ordenamiento socio ambiental sostenible. Para ello es necesario el reconocimiento y apoyo a las Zonas de Reserva Campesina ((ZRC)) y demás formas de asociatividad solidaria. (La Oficina del Alto Comisionado para la Paz, 2016).

Es por la incorporación de la figura de las (ZRC), en el proceso de paz, que tiene la trascendencia en la investigación, también por el papel que le reconoce al campesino con la reactivación del campo y, en especial, el desarrollo de la agricultura campesina, familiar y comunitaria con el planteamiento de la Reforma Rural Integral - RRI, marco para la implementación de acciones y medidas en favor de la población campesina más vulnerable.

Con base en los eventos recientes es que la comunidad del Sumapaz tiene para culminar la consolidación de procesos sociales y comunitarios de desarrollo, bajo el auspicio de las negociaciones, pues fue a través del momento estratégico que el gobierno retomó el procedimiento. Ya que como se manifestaba 
en la audiencia del 27 de agosto, es a través de iniciativas como estas que el campesinado se fortalece y empodera de forma asociativa en organizaciones de base, y se afianza para mejorar tanto las condiciones de vida propias como la del resto de la población, al ser la despensa agrícola para la nación, sino el precursor del páramo y de las fuentes de hídricas de la región.

No obstante, los cambios institucionales del gobierno nacional, frente al sector agropecuario, son recientes y aun incipientes, pues las instituciones creadas están en etapa de conformación y planeación, tanto administrativamente como políticamente, para adherirse a los lineamientos de la política sectorial y al plan nacional de Desarrollo, que tiene como factor la reducción de presupuesto del año 2017 de inversión para agricultura.

\section{DESARROLLO DEL TRABAJO}

\subsection{Reseña histórica de la dinámica campesina en Colombia}

El papel de la normatividad en materia agraria y las intenciones movilizadoras demandantes de los derechos campesinos en la historia de la segunda mitad del siglo XX, se entreteje por la falta de acción e inefectiva del Estado en el ámbito rural, situación que agudiza el problema agrario, convirtiéndose en uno de los principales factores que causan la actual confrontación armada y social en los territorios rurales.

Ejemplo de estas transformaciones y evoluciones, es la relación existente entre el conflicto armado y el problema agrario, agudizado en por otros fenómenos sociales y económicos como la pobreza, además del narcotráfico. Según Fajardo (2002) en Colombia se pasó de la lucha por la tierra y por la violencia política, a una disputa territorial por la cadena productiva del narcotráfico, elementos que se relacionan íntimamente con los habitantes a partir de las representaciones con la tierra y el ejercicio pleno de derechos.

Por lo tanto, los problemas sociales recientes asociados al conflicto armado, tienen raíces históricas relacionadas con momentos determinantes de la cuestión agraria, las agitaciones sociales y agrarias de los años veinte y treinta del siglo XX; la violencia bipartidista de mediados de siglo; los intentos frustrados de reformismo durante el Frente Nacional (FN) y la movilización campesina por la tierra de los años setenta; la articulación definitiva entre el problema agrario y el conflicto armado en los años ochenta y noventa, finalmente, el vínculo del conflicto armado con el narcotráfico y su etapa más reciente de disputas y alianzas por las economías regionales de la coca.

De ese modo, para mitigar la tensión rural, se impulsó la Ley 200 de 1936. Lo cual, a través de la política de La Revolución en Marcha, no sólo le permitió legalizar títulos de propiedad baldía a latifundios sino, que también permitió la adquisición de parcelas a arrendatarios y la normalización de los colonos, pues, cómo la explica Albán (s.f), el propósito consistía en atacar la improductividad de la tierra más no su subutilización. A pesar del carácter marginal de estas medidas, generaron una férrea oposición de los gremios agricultores del partido Conservador y ciertas facciones del Liberal, lo que llevó a López Pumarejo a frenar la iniciativa distributiva.

Esta resistencia quedaría plasmada en la Ley 100 de 1944, que dio reversa al ímpetu reformista de López Pumarejo e incluso llega a ser catalogada como una verdadera contrarreforma agraria (Albán s.f), pues se dejó de lado la intención de convertir al latifundio en una empresa agrícola y reafirmó nuevamente las relaciones de aparcería, tendiendo a polarizar nuevamente la situación en el campo para los años 40 (Arango, 1986, 1987).

Como respuesta a este proceso, el campesinado que había sido expulsado de sus predios por la Violencia de mitad de siglo, empezó a cuestionar el nuevo orden y la nueva la fisionomía de la estructura agraria colombiana, organizándose no solamente en las conocidas autodefensas campesinas y las llamadas Repúblicas Independientes sino también en cuadrillas lideradas por reconocidos bandoleros sociales que cuestionaban la predominancia de latifundio.

Es así que, con los anteriores procesos sociales y agrarios han tenido su origen en la formulación de las diversas políticas públicas, que evidencian la gradual convergencia entre el problema agrario, correlación el conflicto armado y el narcotráfico. En los años sesenta y setenta, el proceso reformista de las estructuras 
sociales y políticas del agro colombiano de Lleras Restrepo fue suspendido por el Pacto del Chicoral y reemplazado por el plan de Desarrollo Rural Integrado (DRI), así como, una inclinación más liberal por la agricultura comercial en detrimento del campesinado.

Luego de finalizada la lucha sectaria campesina con la dictadura de Rojas Pinilla, es el Estado colombiano quien se propuso impulsar algunos programas de colonización, de rehabilitación y de amnistía en las zonas de mayor conflictividad (Cundinamarca, Tolima, Valle del Cauca, Magdalena Medio, Llanos Orientales), sin embargo, estas iniciativas fueron un rotundo fracaso no sólo en materia de redistribución, sino que también, no redujeron los niveles de violencia, puesto que el anticomunismo de Rojas Pinilla condujo a la reactivación de la Violencia por sus ataques a las regiones de influencia comunista, especialmente en el Sumapaz y el oriente del Tolima, que solo iría disminuyendo de manera gradual con el pacto bipartidista del Frente Nacional narrado por (Sánchez, 1990), sino también como efecto de los movimientos mundiales anticomunistas en américa.

Es así que, para finales de la década del 50 `s el ámbito rural colombiano se encontraba atravesado por los coletazos del bandolerismo social (Violencia tardía) (Sánchez, 1990) de grupos de autodefensas campesinos que no eran más que el resultado de la desorganización de las organizaciones populares en un cambio masivo en la tenencia efectiva de la tierra. La convergencia de estos dos procesos se manifestó en un ambiente de tensión social y política en el campo, que como vería los próximos años, emergerían nuevos movimientos, conflictos protagonizados por grupos heterogéneos (aparceros, indígenas, colonos, etc.)

Puesto que los años 60`s el contexto sociopolítico presentaba más violencia y si bien este pacto del Frente Nacional se mostró exitoso en cuanto a ponerle fin la lucha bipartidista (González F, 2010) cuenta como al haberse establecido el reparto pacífico del poder y la obligatoria distribución paritaria de los puestos públicos entre los Partidos Liberal y Conservador, tuvo como resultado la exclusión de toda fuerza política no matriculada en los dos partidos tradicionales entre ellos los colonos. El gobierno de Lleras Camargo, consiente del contexto que lo precedía, no interpretó a la violencia bajo una sólo mirada: la del sectarismo político, también consideró que este fenómeno encerraba tensiones sociales y económicas que tenían su mejor expresión en el mundo rural colombiano.

Para esto, administración de lleras decidió adelantar una serie de programas sociales y económicos diseñados para rehabilitar las zonas del país golpeadas por la Violencia y para acelerar el ritmo de crecimiento económico nacional, dentro de este cuadro se enmarca el intento reformista de Lleras, que no sólo consideró necesario afectar la tenencia de la tierra con el fin de establecer explotaciones medianas y pequeñas sino también para retener a la población en el campo a cuenta del inusitado proceso de urbanización que experimentaba el país, así como por el temor al surgimiento de movimientos campesinos radicales que se defendían de la violencia oficial y el avance electoral del Movimiento de Restauración Liberal (MRL).

Estas medidas se vieron reforzadas por el contexto internacional de la Guerra Fría y la Revolución Cubana, por lo cual, el gobierno en conjunto con los EE.UU promovió la Alianza Para el Progreso (APP), cuyo eje central explicado por (Machado, 2011) se puede decir, era el impulso de una serie de reformas agrarias y tributarias aparejadas con una ampliación de los mercados y la configuración de nuevos espacios para el desarrollo del capital que tendrían como resultado una profundización de la democracia.

Con lo que se dio inicio a un período reformista institucional con la promulgación de la Ley 135 de 1961, la cual creo el Instituto Colombiano de Reforma Agraria INCORA, que adquirió un papel protagónico en la función pública del mercado de tierras y los problemas agrarios, Ley que estableció población objetivo y los territorios afectados, con el propósito de reducir la concentración de la tierra, fomentar una adecuada explotación de tierras incultas o deficientemente explotadas y la creación de mejores condiciones de los asalariados agrícolas es decir, era una iniciativa que buscaba la distribución de la tierra en zonas de colonización y la redistribución de la propiedad al interior de la frontera agrícola.

A pesar del carácter distributivo de la reforma, estas generaron una serie de tensiones y conflictos en el campo colombiano que no 
incluyeron sólo a los propietarios y campesinos sino que también, involucraron al poder central y a los políticos regionales. Estos últimos no sólo asumieron una postura selectiva frente a las políticas del poder central sino que además, trato de impulsar una imagen rebelde dentro del campesinado hacia el Estado.

Fue con la Ley 1 de 1968 que se buscó acelerar la expropiación de los predios mal aprovechados y la adjudicación a los campesinos, se reconoció y organizó al campesinado en la Asociación de Usuario Campesinos (ANUC) cuyo objeto fue agrupar al sector campesino para canalizar las reivindicaciones y así mismo, apoyara las acciones del institucionales del INCORA, la cual con el paso de los años generó sus propias dinámicas y exigencias, como respuesta se dieron una ola de invasiones en los primeros años de la década del 70 , al punto que se estima que fue la movilización más importante en el siglo XX en el país.

Con la Polarización rural de los $70^{\prime}$, el sesgo al campesino sobre modelo de desarrollo agrario, se inicia con un periodo de freno y desmonte de la reforma agraria que es precedido por una incitada ola de invasiones y protesta social campesina, así como el surgimiento de las acciones reivindicativas indígenas, en varias regiones del territorio colombiano, principalmente en la Costa Caribe, Cundinamarca Huila y Tolima, por el poco avance de la reforma en las regiones donde mayor presión por la tierra había, como respuesta al auge de su movilización y organización, que se expresó en un auge de la movilización campesina.

La respuesta que frenaría esas situaciones seria la Ley 6 de 1975, conocida como la Ley de Aparcería que tuvo como objetivo la neutralización de las impugnaciones a la propiedad que venían haciendo los aparceros debido a que se reglamentaba la relación de sujeción y no permitía cualquier tipo de reclamo por la mejora realizada a un fundo ya que revivió la figura del contrato de aparcería.

Posteriormente, durante los años 80`s el tema agrario no fue una prioridad para el gobierno nacional al reto que planteaba para ese entonces la expansión del movimiento insurgente (principalmente el ELN y las FARC), que avanzaba desde sus bastiones históricos a zonas más integradas a la vida política y económica nacional, teniendo como resultado la alteración del orden público en varias zonas del país, en esa vía se puede entender la Guerra del Caquetá y las distintas campañas cívico militares que se adelantaron y contemplaron como medida el Estatuto de Seguridad, que tenía como principal objeto hacerle frente al auge del accionar insurgente y debilitar a sus redes de apoyo, pero el cual terminó estigmatizando aún más la movilización campesina al calificarla como una extensión más del movimiento armado revolucionario.

Es por eso, que el problema agrario sería un tema fundamental en los años 90`s visto como un nodo central en la política nacional según Gros C, Cusminsky R (1988 p.292) inicia por la premisa de atender las zonas propensas y afectadas por el conflicto armado, la política de Paz del presidente de la época Belisario, que implementó en varias regiones del país el Plan Nacional de Rehabilitación (PNR), que además de diagnosticar regiones como el Magdalena Medio, el Urabá, el Cauca, entre otras, buscó implementar planes de desarrollo económico de emergencia en las regiones afectadas, cuyo resultado, sobre la concentración de la propiedad de la tierra señalaban que durante el período 19701984.

En medio de la Asamblea Nacional Constituyente se enfocó la reestructuración de la economía colombiana, surgió la Constitución Política Nacional de 1991, con el esquema constitucional de Estado Social de Derecho, así se plantea el paradigma en que el Estado tiene la obligación de proteger los derechos fundamentales así como también los derechos económicos, sociales y culturales (DESC) de los ciudadanos, (Machado, Vásquez y Núñez, 2005) abriendo la puerta una reforma agraria a través de la Ley 160 de 1994.

\subsubsection{El surgimiento ZRC}

Con el nuevo paradigma constitucional, se renovó el debate sobre los derechos de los campesinos, en lo relativo a la carta constitucional, en lo que se establece, la responsabilidad del Estado para garantizar el acceso a la tierra y la protección de la propiedad privada, con una prioridad a las actividades agrícolas y es desde ahí que resulta trascendental cómo ha evolucionado la lucha campesina en respuesta a los nuevos mecanismos jurídicos. 
A raíz del cambio estructural del constitucionalismo colombiano, el conflicto por parte de la población campesina dejó de limitarse a las luchas tradicionales por la tierra y las políticas agrícolas, se expandieron a las luchas y movilizaciones por la reivindicación de los derechos humanos y el cubrimiento de los Derechos económicos sociales y culturales de los trabajadores agrarios.

Razón por la cual, durante el período comprendido entre 1991 y 1994 se llevaron a cabo 158 luchas agrarias, en medio de las cuales se efectuaron 27 paros cívicos, 82 movilizaciones ciudadanas y 43 tomas de entidades públicas, que involucraban a la población campesina cifras citadas por (Archila, 2005), esto como manifestación de la inconformidad histórica. Es allí, donde (Salas y Zorro, 2012) marcan que la población campesina inicio el proceso de reivindicación, en el marco del movimiento social colombiano debido a las multitudinarias marchas realizadas al largo de los 90's como respuesta a la estrategia de erradicación de los cultivos de coca a través de las fumigaciones con glifosato, situación que aun hoy está en discusión en el territorio colombiano.

Fue así que, una movilización permanente se retomó, especialmente en aquellas regiones afectadas por la siembra de cultivos de uso ilícito, que dieron ejemplo a los antecedentes de la Macarena, como lo narra (Molano, 1989), pues cerca de 20 mil campesinos y colonos de la reserva ecológica que basaban su sustento en el cultivo de hoja de coca, época en la cual vivía una crisis, razón por la cual marcaron y protestaron en el municipio de San José del Guaviare, demandado del gobierno nacional alternativas de crédito, servicios públicos, facilidades de acceso a tierras dentro de la reserva y vías de transporte, elementos que en el momento no existían. Esto debido a falta de figuras e instrumentos que permitieran la interacción directa de las instituciones y las necesidades del campesinado, situación que se acompañó de represalias armadas por parte de las autodefensas.

En consecuencia, de la marcha de la Macarena el gobierno expidió el decreto Ley 1 de 1989, en el cual se declara el área de manejo especial La Macarena y la reserva sierra de la Macarena, especificando las áreas y las condiciones ambientales aplicables, con el fin de amenorar la tensión popular. Pero no logro ponerse en marcha inmediatamente, por lo que según fajardo
(2000), citado por Arévalo (2011) se presentó una propuesta al en su momento gerente del Instituto Colombiano De Reforma Agraria INCORA, que finalmente se convertiría en la figura (ZRC), incorporada en la Ley 160 de 1994.

Igualmente, a través de la Ley 160 de 1994, se planteó por (Instituto Latinoamericano para una Sociedad y un Derecho Alternativo -ILSA. 2013) no se podría afirmar que las (ZRC) en sí, constituye una forma reforma a la estructura de distribución de la tierra, pero sí, contribuyen positivamente a que el latifundio merme la ocupación baldíos y permite un acercamiento importante a la garantía y goce efectivo del derecho a la tierra y los derechos económicos, sociales, culturales y ambientales al campesinado

Luego de esto, dos años de creada la figura de las Zonas, uno de los hechos más importantes, fue donde los problemas rurales y de conflicto convergen con mayor claridad, en las protestas de la base social campesina tras la producción y comercialización de la coca debido a los condicionamientos del gobierno de los Estados Unidos para promover la fumigación de los cultivos ilícitos y los fuertes controles contra los insumos para la producción de Cocaína durante la década de los 90's, que terminaron por llevar a las regiones cocaleras a una profunda crisis económica y social, que se expresaría a través de las llamadas marchas cocaleras de 1996 y 1997, duramente reprimidas por la fuerza pública, pero que ponían en evidencia que detrás de la guerra contra las drogas, se combatía no sólo a los narcotraficantes y guerrilleros, sino a miles de campesinos en las zonas de colonización que encontraban en el cultivo de coca una economía campesina viable y rentable frente a la pobreza, que según (Ramírez, 2001) se adaptaba a los problemas de atraso de la ruralidad en Colombia.

Debido a las marchas que reunió a más 130.000 campesinos durante los años de por 1996 y 1997, con la reglamentación del Decreto 1777, se generaron los espacios para que las comunidades solicitaran formalmente ante el Instituto Colombiano De Reforma Agraria INCORA la constitución de las (ZRC), de cuatro principales zonas en la cual se planteada y complementada procedimentalmente a través del acuerdo 024 también del 1996, la participación de otros entes públicos, como los Consejos Municipales de Desarrollo Rural - CMDR, otras instituciones públicas locales o regionales 
y organizaciones privadas no sin presentarse oposiciones que presentaron polémica como lo describe (Fajardo, 2002).

Adicionalmente, ANZORC (2011) planteo que La figura de ZRC tiene su esencia en el reconocimiento estatal de las luchas agrarias que se han desarrollado desde hace varios siglos. Sin embargo, como propuesta esta figura fue elaborada inicialmente por los campesinos de la región del Duda (Meta), cuando se inició la preparación de la Ley 30 de 1987, en donde plantearon al gobierno la necesidad de crear instrumentos de protección para sus parcelas, frente a la presión de los latifundios, garantizando una oferta adecuada de servicios

Como producto de la presión campesina y gremial del sector agrario de base, formuladas las solicitudes de constitución de las primeras (ZRC), se inicia el denominado Proyecto Piloto de Constitución de (ZRC) en el año 1998, el cual desarrollo la primera experiencia metodológica para las primeras, dada la falta de experiencia del gobierno colombiano en su implementación, con el fin de constituir de manera participativa y operativizar el concepto de las (ZRC).

De acuerdo a esto, se detenta una correlación histórica entre las (ZRC) y las luchas, manifestaciones y movilizaciones organizativas campesinas, las cuales con la consolidación de las (ZRC) dentro del ordenamiento jurídico y la constitución de algunas. Marco un logro extraordinario en el largo camino de la reforma agraria en el país, elemento que se fortalece, constituye y afianza a nivel social y político necesario en la búsqueda de la justicia social y ahora de la paz.

Luego de la expedición de la Ley 160 del 1994, a la fecha se han constituido 6 zonas, mediante el Proyecto Piloto de Zonas de Reserva Campesina (PPZRC) se contó con el apoyo del INCORA, para la creación de las otras tres primeras zonas como lo fueron, el sur de bolívar en Arenales y Morales, bajo Cuembì y comandante o (ahora perla amazónica) en Puerto Asís, Putumayo y por último la del Valle del Rio Cimitarra en el Magdalena Medio. Logrado también través de la manifestación campesina y lucha agraria abierta en los años 90`s lo que trasciende a que según los registros se intervino en 831.111 hectáreas a un total de 99.406 personas inicialmente registradas en las constituciones.

Desde el comienzo de la divulgación de la figura, produjo reacciones de sectores agros empresariales, ganaderos, agrícolas y campesinos en oposición a que la figura se perfilaba como una propuesta técnica y geopolítica novedosa por su idea centrada en el manejo sostenible del territorio y de reforma agraria. Situación inicial que se detuvo como se evidencia, con la constitución de la última ZRC, en el año 2002 y que coincidentemente marca el inicio de un periodo de gobierno, que se caracterizó de todo menos de una vocación social y agraria compatible con el campesinado.

Ya para los años 2000, enmarcado en la Ley 709 de 2002, se adelantó una serie de reformas que llevaron a la liquidación del INCORA, el Fondo de cofinanciación para la Inversión Rural DRI, el Instituto de pesca y Acuicultura, el Instituto Nacional de Adecuación de Tierras, una serie de instituciones que vendrían a ser reemplazadas por INCODER, a partir del Decreto 1300 de 2003 como una entidad de orden nacional adscrita al Ministerio de Agricultura y Desarrollo Rural, con el propósito de ejecutar la política agropecuaria, facilitar el acceso a factores productivos y articular el actuar institucional que agrupo.

Situación que, para el año 2010, luego de un encuentro nacional realizado en Barrancabermeja, se debatiera la suspensión realizada a la ZRC del Valle del Rio Cimitarra, sentado oficialmente mediante el Acuerdo 240 de 2011 del Consejo Directivo del INCODER, lo anterior como manifestación de voluntad gubernamental al cambio de gobierno, como parte del anuncio de la aparente reactivación de la política agraria en cuestión de ZRC, que adicionalmente recogió el inicio del trámite nuevas zonas entre ellas la de la región del Sumapaz, caso que se analiza.

En realidad, desde el año 2003 hasta el año 2015, el INCODER, tuvo una gestión misional salpicada por escándalos de corrupción, noticias e investigaciones que desprestigiaron la institucional a tal punto que mediante la Ley 1753 de 2015 Plan Nacional de Desarrollo, reviste al Presidente de la República de facultades extraordinarias que a través del Decreto 2365 del 7 de diciembre de 2015 Por el cual se suprime el INCODER y se ordena su liquidación. Evento que nos sitúa hoy día, ante un escenario de cambios, 
para dar paso a dos nuevas entidades, como lo propone el Plan Nacional de Desarrollo 2014 2018 del gobierno actual.

Actualmente el INCODER, ahora en Liquidación deja en proceso y tramites de constitución de nuevas Zonas en varias regiones de la geografía colombiana. Sin que todavía estas sean una realidad, estas iniciativas tienen la misma particularidad de provenir de las comunidades, es su demanda de prioridades al Estado. Entre los nuevos procesos se encuentran alrededor de 14 iniciativas reconocidas, entre ellas la del Sumapaz, retomados por la Agencia Nacional de Tierras ANT.

\subsubsection{La evaluación como metodología de investigación}

El punto elementalmente de análisis, es el concepto de evaluación entendido como; la forma de identificar, describir y medir los resultados y los efectos de un programa, actividad o proyecto de forma sistemática y objetiva, lo que se busca también es determinar la relevancia social y jurídica de las instituciones y la satisfacción y cumplimiento efectivo, donde se pueda visualizar y analizar el impacto resultante.

El anterior concepto de evaluación, se refiere a la acción y a la consecuencia de evaluar, un verbo cuya que permite indicar, según el diccionario de la real academia española, los conocimientos, aptitudes y rendimiento del objeto o sujeto estudiado. Pues la evaluación sirve de complemento cuando se quiere analizar y conocer las tendencias de la realidad social.

En un contexto socio jurídico, la evaluación sistemática y objetiva de las políticas públicas y de las normas, comprenden conocer la forma en que estas se relacionan y el rol del sujeto al que se dirige la norma, cuya relevancia se encuentra en los resultados que se obtiene luego de determinar la relevancia con la que la norma llega al sujeto, postulando como objetivos de la norma jurídica, su desarrollo, valido, eficiente, sostenible y efectividad, elementos que a su vez aportan la sostenibilidad.

\subsubsection{El concepto de campesinos.}

Por otra parte, el derecho se debe a la sociedad, para el caso concreto esa parte de la sociedad a la que se refiere la investigación, es aquella que se ubica en el campo, a los que siembran y labran la tierra, el campesino, sujeto social, político, económico, es el individuo, motor rural de iniciativas, personas con igual condiciones.

Más aún, bajo el precepto constitucional según el cual, es deber del Estado promover el acceso progresivo a la propiedad de la tierra de los trabajadores agrarios, así como otros servicios públicos, con el propósito de proporcionar ingresos y mejorar la calidad de vida de la población campesina para desarrollar estos deberes estatales se propone.

Considerando que, (ONU, 2013) reconoce, aprueba y define a nivel internacional la definición general, de campesino de la siguiente manera:

Un campesino es un hombre o una mujer de la tierra, que tiene una relación directa y especial con la tierra y la naturaleza a través de la producción de alimentos u otros productos agrícolas... trabajan la tierra por sí mismos y dependen sobre todo del trabajo en familia y otras formas en pequeña escala de organización del trabajo... están tradicionalmente integrados en sus comunidades locales y cuidan el entorno natural local y los sistemas agroecológicos. (ONU, 2013. Artículo 1 numeral 1)

En síntesis, este documento, tiene especial énfasis en la función social, no de la propiedad sino del sujeto que trabaja la tierra, de la lucha social y del sistema agroalimentario, en el numeral 2, El término campesino puede aplicarse "a cualquier persona que se ocupe de la agricultura, la ganadería, la trashumancia, las artesanías relacionadas con la agricultura $u$ otras ocupaciones similares en una zona rural, a las personas sin tierra" y los califica bajo el entendido de familia como unidad básica. Siendo esta la única definición oficial a la fecha que se tiene de campesino.

En vista de que, según cifras del (IDPAC, 2011) los campesinos del representan el $77 \%$ en el país, estos ocupan solo el 13\% de las tierras con vocación agropecuaria, a lo que se desencadena un problema de concentración inequitativa de la propiedad. Pues como lo expone esta cartilla, más de 11 millones de personas en Colombia son campesinos.

\subsection{4. ¿Que son las Zonas de Reserva campesina?}

Esta figura, podría definirse más ampliamente, como: el instrumento para 
construir y conservar la identidad campesina, las familias modos de vivir, creando un patrimonio cultural que se relaciona con la visión del mundo, las creencias y las normas que tiene la población campesina; ese patrimonio cultural es todo lo que la población ha podido producir (testimonios arquitectónicos, ritos, mitos, símbolos, música, juegos, creencias, conocimientos ancestrales, formas de producción, formas de organización, entre otros). El rescate de la identidad les permite a los campesinos lograr el reconocimiento social como resultado de la interacción cultural al interior de la propia comunidad. A partir de la identidad, los colonos campesinos fortalecen sus valores y mejoran las relaciones existentes.

Para esto, se implementa como un mecanismo de ordenamiento social y productivo del territorio rural, que parte de iniciativas agrarias, constituido en áreas geográficas con características agroecológicas, socioeconómicas, culturales y ambientales especiales, en las que se busca impulsar la Reforma Rural Integral, mediante alternativas participativas, concertadas y equilibradas entre la economía campesina, familiar y comunitaria y el medio ambiente, en un marco de derechos humanos y paz.

En dichas áreas geográficas las características agroecológicas, socioeconómicas, culturales y ambientales señaladas en la ley, hacen referencia a: i) la preexistencia de procesos de colonización y predominio de comunidades campesinas, ii) predominio de tierras baldías, iii) necesidad de regulación, limitación y formalización sobre predios rurales, iv) existencia de conflictos sociales a superar, v) prácticas agropecuarias $\mathrm{y}$ ambientales que deban tender hacia un ordenamiento socio ambiental sostenible, vi) áreas donde se adelantare procesos de restitución jurídica y material de tierras a víctimas del conflicto armado interno, vii) redes sociales y productivas que contribuyan a la generación y consolidación de la reforma rural integral participativa, viii) agro biodiversidad.

Que podrán adjudicarse bajo extensiones mínimas y máximas determinadas en Unidades Agrícolas Familiares (UAF), el número de éstas que podrá darse o tenerse en propiedad, los requisitos, condiciones y obligaciones que deberán acreditar y cumplir los ocupantes de los terrenos. Según lo establecido en el artículo 80 de la Ley 160 de 1994 y decretos reglamentarios

Asociado a esto, el Instituto Latinoamericano para un Derecho y una sociedad Alternativos (ILSA, 2013), esboza una definición adicional en la define como una figura que pretende establecer áreas continuas de fincas campesinas ya sea que sus responsables se encuentren previamente establecidos o que se asignen y titulen a nuevos pobladores. En estas fincas se impulsarán proyectos de producción y comercialización, en rubros conocidos por los campesinos, cuya implementación sea viable económica y ambientalmente. Complementarán el proyecto componentes institucionales de crédito, vivienda, educación, infraestructura y otros servicios referidos en Cartilla Figuras de gestión del territorio (2012).

\subsubsection{Los derechos de los campesinos}

En cuanto a derechos humanos, la población campesina, constituyen un grupo social específico en condiciones de vulnerabilidad, debido a esto requieren de una mejor comprensión y protección, requiere de medidas inclusivas para asegurar que el Estado colombiano.

El derecho se basa un orden normativo e institucional que busca regular toda conducta de las personas en sociedad, como lo explica Céspedes (2010). En este sentido los derechos humanos se pueden definir como cualidades inherentes a todos los seres humanos, sin distinción alguna de nacionalidad, lugar de residencia, religión, lengua, origen nacional o étnico, color o cualquier otra condición, sin discriminación alguna. Estos derechos son interrelacionados, interdependientes e indivisibles tal como se estableció por (ONU, 1948) en la declaración universal de los derechos humanos.

Es así que, de los movimientos sociales, han sido fuente para el reconocimiento de derechos humanos, civiles, políticos y económicos, de los actuales sistemas modernos, los cuales se pueden clasificar en tres grupos de que corresponden a tres generaciones, a saber: derechos humanos de primera generación, o derechos civiles y políticos; derechos humanos de segunda generación o Derechos Económicos, Sociales y derechos humanos de tercera generación, o los derechos de la solidaridad o de la fraternidad, vistos desde (Naranjo, 2006 Cap. IV). Para brindar una idea, general sobre el ámbito 
las cualidades inherentes de las personas bajo el marco constitucional, las libertades sociales para el ejercicio efectivo de los derechos bajo un sistema garantista y la relación armónica con las autoridades públicas responsables.

Acerca de los Derechos Económicos Sociales y Culturales DESC, que refiere la normatividad de las ZRC y desglosados en el marco legal, tienen que ver con el desarrollo de condiciones básicas de la dignidad humana como la posibilidad de tener un nivel de vida adecuado. Dentro de estos se encuentran derechos como la educación, la vivienda, la alimentación, la salud y el trabajo, entre otros. Es así que (Céspedes, 2010) afirma que a partir del reconocimiento de aquellas condiciones fundamentales sociales que se requieren para vivir de manera plena, es decir aquellas condiciones que cuando se cumple le permiten al ser humano su realización en condiciones dignas reales.

Además los campesinos, como sujetos de derechos, en especial de DESC, constituyen un grupo social específico, en condiciones de vulnerabilidad y marginalidad por lo tanto el enfoque progresivo de los Derechos campesinos, requiere de normas e instituciones más efectivas con medidas especiales que permitan asegurar y garantizar su ejercicio.

Por lo tanto, los derechos económicos, sociales y culturales deben alcanzarse progresivamente fundamentados en el principio internacional de la realización progresiva de los derechos, encaminada en la obligación de asegurar condiciones, recursos $\mathrm{y}$ materiales que permitan avanzar gradual $\mathrm{y}$ constantemente hacia la más plena realización efectiva y legitima. Además, el desarrollo progresivo de los derechos no se limita a los DESC, sino desde que abarca desde los derechos fundamentales, es por eso que el principio de la progresividad es inherente a todos los instrumentos de derechos humanos a medida que se elaboran y amplían. Los tratados sobre derechos humanos con frecuencia incluyen disposiciones que implícita o explícitamente prevén la expansión de los derechos en ellos contenidos.

\subsubsection{Principio de Efectividad de los Derechos}

Bajo los postulados del Estado Social de Derecho Colombiano, el logro de los objetivos $\mathrm{y}$ fines del Estado, es la prioridad bajo un ideal democrático, realizando una prestación oportuna y eficaz de los derechos, en la prestación del servicio público. Como se reseña en el marco jurisprudencial mediante la Sentencia del a Corte Constitucional No. (T 068/1998. M. p. Alejandro Martínez Caballero) que desarrolla este principio, desde el caso de una acción de tutela.

Para cumplir con la obligación de garantizar y promover los derechos Económicos, Sociales y Culturales de los campesinos, el Estado, debe desarrollar una Estrategias enfocadas en la ampliación del marco normativo de estos derechos y en la ampliación de mecanismos eficientes y eficaces de protección y exigibilidad hacia los DESC.

Expuesto por la Corte Constitucional en la Sentencia (T 068/98. M.P Alejandro Martínez Caballero) donde la definición de efectividad, tiene importancia en las normas jurídicas de carácter social dentro de la teoría de la norma jurídica, según (Bobbio, 1990) surge el problema de sí una norma es o no cumplida sus destinarios, evento que sería ineficaz especifica que para lograr identificar si una norma es o no eficaz es necesario una revisión histórico social, para determinar la el comportamiento de la sociedad en relación con la norma. A su vez expone otros criterios de valoración normativa como la validez y la justicia. Por lo que manifiesta las premisas de "Puede una norma ser Justa sin ser válida Puede ser válida una norma sin ser justa puede ser válida sin ser eficaz y puede ser Eficaz sin ser válida.

Por lo tanto, la institucionalidad administrativa, necesita cambio un apoyo logístico suficiente, una infraestructura adecuada, un personal calificado y la modernización de ciertos sectores que permitan suponer la transformación de un Estado predominantemente legislativo a un Estado administrativo de prestaciones. Según lo comenta (Céspedes, 2010).

Para entender mejor y hacer las reflexiones pertinentes, es apoyado en lo definido por (Correas, s.f, citando a Kelsen) como la eficacia del Derecho y la efectividad de la norma, es así que el derecho emanado de forma regular es legal dentro del sistema es legítimo mientras respete el orden y la legalidad. Pero es las normas sujetas de efectividad, mediante la verificación empírica observable, sencillamente desde el hecho que la conducta sea efectivamente realizada o no, 
que cuya producción u omisión obligada sea generada, ante el enunciado normativo que exige su efectividad, en un sentido de obediencia que se despliegue dentro de la norma en armonía con el sentido y objetivo de sistema o derecho desarrollado. Obteniendo así el resultado previsto y los objetivos de conseguir lo que se planteó.

El ordenamiento territorial a nivel rural pretende establece que mediante la constitución de ZRC, se trata de impedir la concentración de la propiedad y controlar el crecimiento de la frontera agraria así estabilizar el frente colonizador. Por lo cual se podría afirmar que los procesos de ampliación de la frontera agrícola en Colombia han sido motivados por conflictos sociales y de interés económico, determinando condiciones que han incidido la reducción de su dinamización (Fajardo, 1996).

Reconociendo estos elementos la figura se torna en un instrumento de ordenamiento social, ambiental y productivo de la propiedad rural y del territorio con equidad, mediante la formación, organización y participación ciudadana; la consolidación de redes sociales y la generación de alianzas y relaciones con actores públicos $\mathrm{y}$ privados a nivel local, regional, nacional e internacional, que permitan generar condiciones para el desarrollo rural integral en el marco de los derechos humanos y la paz y desarrollo integral de las regiones en las cuales se implementan.

\subsubsection{Con la constitución Política de Colombia 1991}

La legislación colombiana tuvo nueva connotación respecto al reconocimiento de los derechos fundamentales de los nacionales, protección y garantías para su ejercicio, luego de la promulgación de la Constitución Política Nacional - CPN, de 1991 y de la visión del campesino como sujeto de derechos dentro del ordenamiento jurídico y político del país, relativas a los derechos de los campesinos, de los trabajadores agrarios, a las actividades agrícolas y a los aspectos ambientales, radican en la supremacía y valor jerárquico que posee la Constitución política de Colombia dentro del sistema jurídico como norma de normas, tal cual lo dice el artículo 4 de la CPN.

Por otra parte, el Estado se obligó con la nueva carta a través de las instituciones públicas en garantizar la efectividad de los principios, derechos y deberes establecidos como fines esenciales, desarrollados mediante los instrumentos jurídicos legales que regulan cada materia. Como lo es la obligación del Estado a través de sus entidades ordenar el uso y la ocupación de las tierras rurales con el fin de asegurar la soberanía alimentaria, mejorar la calidad de vida de los habitantes, generar inclusión social y garantizar la efectividad de los derechos sociales, económicos, culturales, políticos y ambientales de la nación.

Para dar cumplimiento a esto, conforme al resurgimiento como base un Estado Social de Derecho, la visión del sector rural, de una política para la reforma agraria y de los campesinos, de los derechos, garantías y mecanismos efectivos para atender la población rural, fueron desarrollados en la Ley 160 de 1994, que re define el concepto de adjudicación de predios baldíos y constituye una nueva forma organizativa rural y territorial como impulso de la económica campesina con núcleo familiar, definidas en el capítulos XII y XIII, dirigido jurídicamente como una estrategia productiva y ambiental con el propósito de estabilizar la frontera agrícola, concentrada en las zonas de reserva campesina.

También en la carta de 1991, con el cambio del modelo de Estado social de derecho, cambio también la visión que se tenía de los campesinos y los derechos, garantías y mecanismos para su lograr su efectividad, de los cuales hoy se encuentran en el título II, de los derechos, garantías constitucionales $\mathrm{y}$ de los deberes, clasificados en tres clases, los derechos fundamentales, los derechos sociales, económicos y culturales y los colectivos y del ambiente. Que constan desde el articulo 42 al 46, 48, 49, 51, 57 60,63 al 66, 67 79, 80 y 82 de la CPN

Principalmente, se encuentra dentro de estos, el Artículo 58 de la CPN, plantea que; el Estado debe propender por el acceso a la propiedad de la tierra por parte de trabajadores agropecuarios y de los campesinos que no tienen tierra o de aquellos que las tienen en ínfimas cantidades. Siendo también uno de los objetivos de la reforma agraria, adicionalmente como medida para frenar el fenómeno de concentración

Frente a esto, inmerso en las cualidades de la propiedad, planteada en el mismo artículo, se encuentra la función social, que consiste en 
explotar económicamente y productivamente la propiedad en los casos de tierras rurales, siendo útil y favorecer en los interesas generales de la sociedad y no solo a la los particulares del propietario del bien inmueble, estableciendo la relación e intervención entre el Estado y los limites jurídicos y sociales de su uso, también estipula la obligación y función ecológica inherente que deben desarrollarse en las actividades económicas de la tierra, sin detrimento de del medio ambiente y como medida de protección constitucional contra el uso irracional de recursos naturales, de actividades contaminantes, limitaciones del derecho a la propiedad frente a terceros y frente a la Ley.

Luego de esto, se encuentra, la función de proteger $y$ promover las formas asociativas $y$ solidarias de trabajar la tierra y de acceder a la propiedad para el fortalecimiento, elevadas por primera vez a canon constitucional por el Constituyente de 1991, en el propósito de alcanzar una nueva estructura social, que permita una mejor redistribución de la riqueza y del ingreso, como lo expresó la Corte Constitucional en la Sentencia C 037 de 1994, como modelo incluyente para el desarrollo económico de la población de una forma más democrática y de una participación activa a la población de bajos recursos, específicamente frente a los procesos de privatización. Por lo que también se ha comprendido a las ZRC, como una alternativa de económica solidaria para el desarrollo rural.

Complementariamente está en el Artículo 64 de la CPN, tiene el deber de promover el acceso el acceso progresivo a la propiedad de la tierra a los trabajadores agrarios, en formas individuales y asociativas, así como el acceso a otros servicios como lo son, la educación, la salud, vivienda, seguridad social, recreación, crédito, comunicaciones comercialización de productos, asistencia técnica y empresarial, con el fin de mejorar los ingresos de los campesinos y de mejorar su calidad de vida.

Vinculado directamente con el Artículo 65 de la CPN, según el cual, el Estado protegerá la producción de alimentos. Como derecho humano a la alimentación que sobre la soberanía alimentaria. Establece que la producción de alimento más aun la calidad de dichos alimentos, tendrán mayor nivel de protección cuando la tierra es apta para dicha función.
Es el Estado el llamado a proteger la diversidad e integridad del ambiente, conservar áreas de especial importancia ecológica y fomentar la educación para el logro de estos fines. En el artículo 79 de la CPN, hace parte del capítulo 3 , que trata sobre los derechos colectivos y del establecer qué; todas las personas tienen derecho a gozar de un ambiente sano y que se vinculará a la comunidad a participar en las decisiones que puedan afectarlo. Adicionalmente, que

A través del artículo 80 de la $\mathrm{CPN}$, regulo el uso de los recursos naturales de manera sostenible, en pro de su conservación y renovación, incorporando la obligación a todos, de proteger la biodiversidad e integridad de los ecosistemas previniendo el deterioro del ambiente, situación que tomara gran importancia, con la presencia del Parque Nacional Natural del Sumapaz, como fuente hídrica mundial comprometida con los megaproyectos y las actividades mineras.

\subsubsection{Leyes y normas reglamentarias de las ZRC}

En lo que corresponde a la investigación, se hace referencia de manera específica a la Ley 160 de 1994, el Decreto 1777 de 1996 y el Acuerdo 024 de 1996, representan el marco jurídico de las Zonas de Reservas Campesinas, lo atinente a la definición alcances y reglamentación y a su procedimiento continuación:

Es así que la Ley 160 de 1994 toma vida jurídica Por la cual se crea el Sistema Nacional de Reforma Agraria y Desarrollo Rural Campesino, se establece un subsidio para la adquisición de tierras, se reforma el Instituto Colombiano de la Reforma Agraria1 y se dictan otras disposiciones publicada en el diario Oficial No. 41.479, de 5 de agosto de 1994 mediante el cual entra en vigencia en el ordenamiento jurídico nacional, inicialmente crea Sistema Nacional de la Reforma Agraria y Desarrollo Rural Campesino Como:

Un mecanismo obligatorio de planeación, coordinación, ejecución y evaluación de las actividades dirigidas a prestar los servicios relacionados con el desarrollo de la economía campesina y a promover el acceso progresivo a la propiedad de la tierra de los trabajadores agrarios, con el fin de mejorar el ingreso y calidad de vida de los hombres y mujeres campesinos de escasos recursos. Implementando un nuevo esquema de 
intervención político a nivel rural, tal como lo reza (Ley 160 de 1994, artículo 2)

Relacionado con lo anterior, uno de los principios de la Ley 160 de 1994, es el ordenamiento social, ambiental y productivo de la propiedad rural mediante el fomento de la pequeña propiedad, el acceso progresivo a la propiedad de la tierra por parte de los trabajadores agrarios, promover y consolidar la paz a través de mecanismos encaminados a lograr la justicia social, la democracia participativa y el bienestar de la población Campesina, Para el caso puntual de la investigación, el numeral noveno se encuentra como parte del objeto de la Ley:

Es Regular la ocupación y aprovechamiento de las tierras baldías de la Nación, dando preferencia en su adjudicación a los campesinos de escasos establecer Zonas de Reserva Campesina para el fomento de la pequeña propiedad rural, con sujeción a las políticas de conservación del medio ambiente y los recursos naturales renovables y a los criterios de ordenamiento territorial y de la propiedad rural que se señalen. (Ley 160 de 1994, artículo 1, numeral 9)

Es dentro del capítulo XIII, denominado Colonizaciones, Zonas de Reserva Campesina y Desarrollo Empresarial desde el artículo 79 hasta el artículo 84, parte donde a través de 6 artículos, se desarrolla las actividades dirigidas al ordenamiento de la propiedad en función del fenómeno de la concentración de la tierra y condiciones para los colonos y de tierras baldías.

Luego de esto en el artículo 80, nos trae la primera definición de las ZRC, definición y alcances que son ampliados mediante las normas reglamentarias en lo relativo a las ZRC.

Las áreas geográficas seleccionadas por la Junta Directiva del Instituto Colombiano De Reforma Agraria INCORA, teniendo en cuenta las características agroecológicas y socioeconómicas regionales. En los reglamentos respectivos se indicarán las extensiones mínimas y máximas que podrán adjudicarse, determinadas en Unidades Agrícolas Familiares, el número de éstas que podrá darse o tenerse en propiedad, los requisitos, condiciones y obligaciones que deberán acreditar y cumplir los ocupantes de los terrenos. (Ley 160 de 1994, artículo 80)
Adicionalmente, el articulo 80 agrega uno de los aspectos más relevantes de las ZRC, para esta investigación y es la conceptualización de la efectividad de las ZRC frente al el ejercicio y aplicabilidad de los derechos Sociales, Económicos y culturales de los campesinos, elementos que tiene la trascendencia en el caso, porque, la finalidad esencial desde el rango constitucional, de las Leyes en el marco de un Estado Social de Derecho es servir a la comunidad, promover la prosperidad general y garantizar la efectividad de los principios, derechos y deberes consagrados en la Constitución; facilitar la participación de todos en las decisiones que los afectan y en la vida económica, política, administrativa y cultural de la Nación; defender la independencia nacional, mantener la integridad territorial y asegurar la convivencia pacífica y la vigencia de un orden justo.

En otras palabras y tal como lo señala Ministerio de Agricultura y Desarrollo Rural MADR, IICA y BM (2003) el agente central de los procesos, no es solamente el campesinado aislado e individualmente, sino la comunidad campesina a través sus organizaciones, representantes colectivos de los intereses sociales dentro del proceso de la consolidación social y económica de los campesinos tanto individual como asociativamente.

La Situación que en forma crítica se desvirtúa con el actuar institucional ineficiente e inefectivo respecto a la figura. Aparte normativo que señala lo siguiente en el párrafo tercero del citado artículo:

En las Zonas de Reserva Campesina la acción del Estado tendrá en cuenta, además de los anteriores principios orientadores, las reglas y criterios sobre ordenamiento ambiental territorial, la efectividad de los derechos sociales, económicos y culturales de los campesinos, su participación en las instancias de planificación y decisión regionales y las características de las modalidades de producción... negrilla fuera del texto original. (CPN, artículo 9)

Con lo anterior se quiere hacer referencia a que la Efectividad de las actividades de la gestión pública, especialmente con lo relativo a derechos DESC, es obligación y fines del Estado, del gobierno y de las autoridades públicas, efectividad que a su vez es exigible y que es imperante en el contexto colombiano en los momentos en que aquellos derechos están siendo desconocidos y vulnerados por el actuar mismo de las entidades. 
Ahora bien, uno de los elementos más cuestionados, debido a que se plantea otra figura denominada Zonas de Desarrollo Empresarial ZDE, planteado en los artículos 82 y 83, zonas que se presentan como una excepción del articulo 81 y que contemplan la posibilidad que se establezcan a través de capital privado para la producción agropecuaria, explotación agrícola o ganadera situación de esta reglamentada mediante el Acuerdo 028 de 18 de diciembre de 1995, define los criterios metodológicos de selección, procedimiento. Sin embargo, pese a los intereses privados en la constitución de las ZDE, en el país al momento no se ha logrado constituir ninguna.

Por último, el capítulo XIII, en lo preceptuado en el artículo 84, se vincula la participación de otras entidades públicas dentro del proceso de constitución de las ZRC, de manera obligatoria, específicamente a las alcaldías municipales, así como las organizaciones representativas de los intereses de los colonos. En las cuales la comunidad actúa protagónicamente en la elaboración, construcción y ejecución de los planes de desarrollo para que en coordinación con las entidades intervinientes gestionen el proceso.

Por otra parte, en el párrafo segundo, prescribe que sobre las reglamentaciones que se realicen estarán a cargo del INCORA, luego INCODER, ahora Agencia Nacional de Tierras ANT, relacionadas con los procesos de colonización y que deberá incluir de manera básica la conservación, protección y utilización de los recursos naturales bajo el criterio de desarrollo sostenible y también las áreas especiales que no pueden ser objeto de ocupación y explotación.

En cuanto a las normas específicas vigentes reglamentarias y regulatorias a las ZRC, se relacionan el Decreto 1777 de 1996 del Ministerio de Agricultura y Desarrollo Rural y los Acuerdos 024 de 1996 y 010 de 1999, que a continuación se desarrollan en sus principales aspectos respecto a su constitución y planificación de la figura.

\section{Decreto 1777 de 1996}

Expedido por el entonces presidente de la republica Ernesto Samper y reglamentó parcialmente el Capítulo XIII de la Ley 160 de 1994, conforme a los artículos 79 al 84, en lo relativo a las zonas de reserva campesina, asignando la competencia a la junta directiva del
INCODER proporciona a su igual que la Ley las características de constitución y delimitación "en zonas de colonización, en las regiones en donde predomine la existencia de tierras baldías y en las áreas geográficas cuyas características y socioeconómicas requieran la regulación, limitación y ordenamiento de la propiedad o tenencia de predios rurales"

Se destaca que el párrafo segundo del artículo 1ro que, el objeto de las ZRC el de fomentar $y$ estabilizar la economía campesina, superar las causas de los conflictos sociales que las afecten $y$, en general, crear las condiciones para el logro de la paz y la justicia social, así como la posibilidad de comprender zonas de amortiguación del área de Sistema de Parques Nacionales Naturales, con el propósito de desarrollar las actividades, modelos y sistemas productivos que se formulen en los planes ambientales establecidos para las zonas respectivas, con opción adicional de realizar las sustracción de áreas de las zonas de reserva forestal establecidas mediante la Ley $2 \mathrm{da}$ de 1959 en los casos hayan sido intervenidas por el hombre, avaladas por la autoridad ambiental competente, previo estudio y solicitud de la Junta Directiva del Instituto.

A su vez señalo en el Decreto 1777 de 1996 los objetivos de constitución de las ZRC, se establecen siete objetivos, textualmente son:

1. Controlar la expansión inadecuada de la frontera agropecuaria del país.

2. Evitar corregir los fenómenos de inequitativa concentración, o fragmentación antieconómica de la propiedad rústica.

3. Crear las condiciones para la adecuada consolidación y desarrollo sostenible de la economía campesina y de los colonos en las zonas respectivas.

4. Regular la ocupación y aprovechamiento de las tierras baldías, dando preferencia en su adjudicación a los campesinos o colonos de escasos recursos.

5. Crear y constituir una propuesta integral de desarrollo humano sostenible, de ordenamiento territorial y de gestión política.

6. Facilitar la ejecución integral de las políticas de desarrollo rural.

7. Fortalecer los espacios de concertación social. Política, ambiental y cultural entre 
el Estado y las comunidades rurales, garantizando su adecuada participación en las instancias de planificación y decisión local y regional. , (artículo 2)

Continuando con el decreto, que a través de solo 6 artículos concreta elementos reglamentarios de las ZRC, definiendo aspectos como formas de financiación o cofinanciación de entidades dentro del Sistema Nacional de Reforma Agraria definidas en la Ley 160 de 1994, de proyectos de utilidad pública e interés social en las zonas constituidas, dentro del Plan de Desarrollo Sostenible de la Zona la necesidad de las características agroecologías y socioeconómicas de la región y de los CMDR Consejos Municipales de Desarrollo Rural.

\section{El procedimiento del Acuerdo 024 de 1996}

Por medio del acuerdo 024 del año de 1996, el INCORA, facultado por la Ley 160 de 1994 se fijan los criterios generales y el procedimiento para seleccionar y delimitar las Zonas de Reserva Campesina. Es a partir de este acuerdo, se estipula en su artículo 1, que la constitución de ZRC se hará en regiones donde se adelanten procesos de colonización, en aquellas donde predomine la existencia de tierras baldías y en las áreas geográficas cuyas características agroecológicas y socioeconómicas.

Con esta última, se amplía el campo de acción de las ZRC, más allá del criterio de colonización y predominio de baldíos de la Ley 160 de 1994 y se extiende a otras áreas que por su particular vulnerabilidad o importancia ambiental o social requieran de un mecanismo similar al adoptado por ellas.

Los criterios de selección de las iniciativas a emprender formalmente, dependen de que no se presenten restricciones expresas señaladas en el Acuerdo 024, en cuanto a traslapes con áreas como del Sistema Nacional de Parques Nacionales Naturales, reservas forestales, territorios indígenas, títulos colectivos de comunidades negras, Zonas de Desarrollo Empresarial ZDE y áreas reservadas para otros fines. Estos territorios que se exceptúan de la posibilidad de constitución de ZRC, eventualmente serían ampliados conforme a lo establecido en el Proyecto de Ley de tierras y Desarrollo Rural, dotando de disposiciones más restrictivas al respecto.
Adicional, a los establecido por el acuerdo 024, el decreto 1777 expone la necesidad de formular como un instrumento de planificación, que comprenda además de las características agroecológicas y socioeconómicas de la región el denominado Plan de Desarrollo Sostenible (artículo 4), el cual define las actividades, programas e inversiones que deberán realizarse por las entidades públicas y privadas y las organizaciones sociales.

Dentro de esta descripción normativa de las ZRC adicionalmente, es importante destacar la función amortiguadora de ZRC que, podrán comprender también las zonas de amortiguación del área de Sistema de Parques Nacionales Naturales, con el propósito de desarrollar las actividades modelos y sistemas productivos que se formulen en los planes ambientales establecidos para las zonas respectivas. En las zonas de coincidencia, estos planes deberán respetar las regulaciones establecidas para las zonas amortiguadoras parágrafo 1, artículo 1, Decreto 1777 de 1996.

El otro aspecto trata, del ordenamiento social y de la tenencia de la tierra en las ZRC, se enfoca hacia la estabilización de la frontera agrícola y generación de arraigo en el territorio, con énfasis especial en la función amortiguadora de las áreas de preservación en zonas de recuperación para la producción mediante la formulación de planes de manejo adaptados a la normatividad y a las condiciones medioambientales y sociales del territorio.

De manera semejante, la ZRC, tiene como esencia; el ordenamiento social de la propiedad, ordenamiento productivo, la zonificación ambiental, erradicación de actividades ilícitas como el cultivo de coca, mediante las cuales se han liberado áreas protegidas para su restauración, contribuyendo a: la conservación de las áreas de especial importancia ecológica como son los Parques Nacionales Naturales; a la protección de las riquezas naturales y culturales de la Nación; la función ecológica de la propiedad; la prevención del deterioro ambiental, protección de ecosistemas y garantía del desarrollo sostenible; y busca entre otras cosas, mejorar las condiciones de vida de la población, al garantizar el desarrollo de actividades que les permite la satisfacción de necesidades básicas, como es acceso a la propiedad privada y la alimentación. 


\subsubsection{Disposiciones legales ambientales de zonas}

Las ZRC son una propuesta para articular las acciones institucionales y sociales en las zonas de amortiguamiento de las áreas protegidas y establecer su priorización y organización con el fin de estabilizar y equilibrar la economía de manera sostenible y sustentable, tanto por la vocación de los suelos como por la composición de ecosistemas, en las cuales el protagonista son las organizaciones y comunidades gestoras comprometidas con la conservación y uso racional de los recursos naturales.

Para empezar, el Decreto Ley 2811 de 1974, es el Código de los Recursos Naturales Renovables y Protección al Medio Ambiente, fundado en el principio que el ambiente es patrimonio común de la humanidad y necesario para la supervivencia y el desarrollo económico y social de los pueblos. La Ley 388 de 1997, en el marco general del desarrollo territorial en los municipios y distritos de Colombia establece los principios del ordenamiento del territorio, los objetivos y acciones urbanísticas, la clasificación del suelo y los instrumentos de planificación y gestión del suelo, en relación con el Sistema Nacional de Áreas Protegidas, el Decreto 2372 de 2010, define las categorías de manejo que lo conforman y se dictan otras y su objeto es reglamentar el Sistema Nacional de Áreas Protegidas, las categorías de manejo que lo conforman y los procedimientos generales relacionados.

Complementariamente, los procesos de sustracción de áreas de reserva forestal sujetas a la regulación de la Ley 2 de 1959 para constituir la ZRC, ya que con la sustracción es una figura que permite ordenar los territorios de una mejor manera para las familias colonas y ocupantes de la tierra caracterizada por el poblamiento de colonos, campesinos y comunidades de desplazados, con características y problemáticas ambientales, agroecológicas y socioeconómicas con diversos arraigos, es otra figura del derecho ambiental relacionada en los proceso de constitución, ejemplo el caso del proceso ZRC del Catatumbo, en el departamento de Norte de Santander.

Es por eso, que el procedimiento para la constitución de las ZRC contempla que las Zonas de Reserva Campesina no pueden constituirse al interior de Parques Nacionales Naturales, como anteriormente se menciona en el Decreto
1777 de 1996, razón por la cual De las 76902,15 hectáreas que abarca la localidad de Sumapaz, 45308,43 hectáreas corresponden al Parque Natural Nacional de Sumapaz, por lo que según ASOSUMAPAZ (2013) menciona en el resumen Ejecutivo del PDS' la ZRC abarcará tan solo el 33\% de la localidad, es decir 25318,82 hectáreas,

De otra parte, la CAR en el área de jurisdicción del Páramo de Sumapaz realizó el diagnóstico ambiental de las zonas rurales de las localidades de Usme y Sumapaz, el cual hace parte del Plan de Ordenación y Manejo de la Cuenca - POMCA del Río Sumapaz que en la actualidad se encuentra en proceso de ajuste en concordancia con el Decreto No.1640 de 2012 del Ministerio de Ambiente y Desarrollo Sostenible, por lo tanto el Plan de Manejo para la zona de amortiguación como el POMCA del Rio Sumapaz, cuentan con los respectivos diagnósticos ambientales requeridos hasta el momento.

También se tiene el Decreto 1729 de 2002, sobre cuencas hidrográficas en ordenación, para el planeamiento del uso y manejo sostenible de los recursos naturales renovables, de manera que se consiga mantener un equilibrio adecuado entre el aprovechamiento económico de tales recursos y la conservación de la estructura físico biótica de la cuenca y particularmente de sus recursos hídricos.

Con el fin de desacelerar el deterioro del ecosistema, la comunidad planteo un PDS diseñado en pro del PNN, forma poder hallar medidas que nos generen el fortalecimiento de acciones encaminadas a la mitigación y adaptación al cambio climático en la zona; por ser este un territorio de importancia fundamental desde el enfoque ambiental.

A propósito de este enfoque, la comunidad planteo unos objetivos establecidos en el Plan de Desarrollo Sostenible de la ZRC en la Localidad del Sumapaz, que (Asosumapaz, 2013), se refiere en el contexto ambiental, el objetivo general de las ZRC, para el proyecto de la comunidad del Sumapaz, se resume así: Fortalecer la gestión ambiental alrededor de las microcuencas de la ZRC de la localidad del Sumapaz, con el ordenamiento ambiental del territorio en las 16 veredas de la localidad 20 que proyectan consolidarse como ZRC

Así como también a través de lo mencionado en el Ley 99 de 1993, se estableció dentro de los principios generales ambientales de la normatividad colombiana en su artículo 1ro, numeral 4) 
Las zonas de páramos, subpáramos, los nacimientos de agua y las zonas de recarga de acuíferos serán objeto de protección especial complementado con lo referido en el artículo 61 esta Declárase la Sabana de Bogotá, sus páramos, aguas, valles aledaños, cerros circundantes y sistemas montañosos como de interés ecológico nacional, cuya destinación prioritaria será la agropecuaria y forestal.

Como consecuencia a la definido en el SINA, fue a través del artículo 16 de la Ley 373 de 1997, que fue modificado por el Art. 89 de la Ley 812 de 2003, se definió la obligación de la implementación de un programa de protección de zonas de manejo especial, para el uso eficiente y ahorro del agua de la siguiente manera "las zonas de páramo, bosques de niebla y áreas de influencia de nacimientos acuíferos y de estrellas fluviales, deberán ser adquiridos o protegidos con carácter prioritario por las autoridades ambientales, entidades territoriales y entidades administrativas de la jurisdicción correspondiente".... Situación que está referida dentro de la Ley 160 y el Decreto 1777 y desarrollada muy superficialmente en el Plan de Desarrollo Sostenible (PDS) de la ZRC del Sumapaz de 2013, situación que se reflexión y evidencio en la audiencia pública llevada a cabo el día 27 de agosto de 2016.

En razón de que gran parte de la localidad 20 de Bogotá, es parte de parque natural del Sumapaz y otra está dentro de las áreas protegidas, es la relevancia jurídica de precisar aspectos ambientales y es también por esto que, a través de la Ley 165 de 1994, se aprobó el Convenio sobre la Diversidad Biológica, hecho en Río de Janeiro el 5 de junio de 1992, sobre el cual se formuló la Política Nacional de Biodiversidad y se establece la obligación de conformar el Sistema Nacional de Áreas Protegidas - SINAP.

Por ultimo dentro de las referencias normativas se tiene a la Ley 1450 de 2011, que siendo el Plan Nacional de Desarrollo 2010 2014, de la actual administración presidencial, desconoció aspectos ambientales de los ecosistemas paramunos, prevaleciendo intereses económicos de proyectos minero energéticos, a través de Ley 1753 de 2015, situación que se analizó y evidencio en el fallo de inconstitucionalidad de la sala plena de la Corte Constitucional Sentencia C 035 de 2016 (M.P. Gloria Stella Ortiz Delgado), donde primo el valor ambiental y la importancia estratégica de los páramos, donde se regulaban el sistema nacional de proyectos de interés nacional y estrategias en materia de reservas mineras y estratégicas, esta sentencia se desarrolla en el marco jurisprudencial.

\subsubsection{Jurisprudencia sobre ZRC}

En Colombia, los pronunciamientos en cuestión de derechos y zonas de reserva campesina luego de la constitución de 1991 a la fecha, luego de la entrada en vigencia de la Ley 160 de 1994 profiriera recientemente con la Corte Constitucional con la sentencia de C 371 de 2014 (M.P. Jorge Ignacio Pretelt Chaljub), donde se demandaron los artículos 80, 81 y 84 de la Ley 160 de 1994, que son los artículos que consagran las Zonas de Reserva Campesina (ZRC) y mediante la discusión dentro del bloque de constitucionalidad y de la necesidad de realizar consulta previa como derecho fundamental de las comunidades indígenas, afrocolombianas, raizales y rom, cuando se vean posiblemente afectadas comunidades étnicas en procesos de constitución de ZRC textualmente dice:

Las Zonas de Reserva Campesina son una figura para la ordenación social, ambiental y productiva de una región. Sus finalidades más importantes son solucionar conflictos socioeconómicos y ambientales ligados a la tierra, evitar su concentración, acaparamiento y fragmentación antieconómica, ordenar la adjudicación de baldíos y orientarla hacia campesinos de escasos recursos, fomentar la pequeña propiedad rural, proteger y fortalecer las economías campesinas, ordenar los procesos de colonización y contribuir a la realización de los derechos económicos, sociales y culturales de los campesinos, como el derecho a la alimentación y al acceso progresivo a la tierra

La Corte se pronunció en el entendido que para la creación de una ZRC debe examinarse si en el área en la que se pretende constituir, existen territorios de pueblos indígenas y tribales o presencia de dichos pueblos, caso en el cual deberá garantizarse el derecho a la consulta previa y advirtió la obligatoriedad de participación de las entidades públicas de garantía dicho derecho a las comunidades indígenas presentes en regiones donde se pretende la constitución de una ZRC.

Es por eso, que en la constitución se prevén los deberes del Estado frente al acceso a la tierra 
y, de manera especial, el acceso progresivo a ella por los trabajadores agrarios, de la misma manera deben ajustarse los mecanismos $y$ sistema normativo para que de esa manera se regularice las situaciones que se presentan, es por esa razón que a través de la Sentencia C 644 de 2012 (M.P. Adriana María Guillen Arango), la Corte Constitucional expuso los motivos por los que declaro inexequibles constitucionalmente los artículos de la Ley 1450 de 2011 , por la cual se establece el Plan de Desarrollo 2010 2014, el tanto de la regresión del derecho de acceso a la propiedad rural de los trabajadores del campo y los derechos inherentes a éste como la vocación de permanencia sobre la misma, en lo que respecta a los mecanismos legales que le permiten a la población acceder al predios baldíos, como el imperativo del Estado social de derecho, en el bien jurídico de proteger los derechos y de mejorar progresivamente las condiciones materiales de existencia de los sectores más deprimidos, como los son el caso de los campesinos y los fenómenos históricos que le anteceden en cuestión de reforma agraria.

A su vez, en el pronunciamiento, la Corte expresa la importancia del campo entendida como bien jurídico de rango constitucional, como una "realidad geográfica, regional, humana, cultural y, económica, que por lo mismo está llamada a recibir una especial protección del Estado", en la Sentencia C 644 de 2012 (M.P. Adriana María Guillen Arango) de la misma entidad, razón por la cual el gobierno nacional debe la adoptar medidas estructurales orientadas a la creación de condiciones para que los trabajadores agrarios sean propietarios de la tierra rural progresivamente.

Es por eso, que siguiendo la tendencia y la línea jurisprudencial y primando el interés social y común, la Constitucional fue a través de la Sentencia C 035 de 2016 (M.P. Gloria Stella Ortiz Delgado), en la cual se analiza la constitucionalidad del articulado 108 de la Ley 1450 de 2011, por la cual se aprueba el Plan Nacional de Desarrollo 2010 2014; y contra los artículos 20, 49, 50 (parcial), 51, 52 (parcial) y el parágrafo primero (parcial) del artículo 173 de la Ley 1753 de 2015, por la cual se aprueba el Plan Nacional de Desarrollo 2014 2018, sentencia en la cual, fue la Corte misma la que declaró la inconstitucionalidad de aquellos artículos de Áreas de reserva minera estratégica, en los que se afectaban al medio ambiente o un riesgo a la sostenibilidad alimentaria de las poblaciones, por lo que prevalece frente a los derechos económicos adquiridos por particulares mediante licencias ambientales y contratos de concesión para evitar un daño a los recursos naturales no renovables y a la salud humana.

Para lo cual cita un concepto de la Comisión Mundial sobre Medio Ambiente y Desarrollo sobre el desarrollo sostenible como ... "aquel que garantiza las necesidades del presente sin comprometer las posibilidades de las generaciones futuras para satisfacer sus propias necesidades"... concepto que gira en torno al equilibrio entre el crecimiento económico, el bienestar social y la preservación de los recursos naturales, que según la misma corte fue recogida en el artículo 80 de nuestra Constitución, adicionalmente desarrollada en los objetivos de las Zonas de Reserva Campesina, como mecanismo de planeación territorial y ambiental.

No obstante, no son recientes, como producto de un momento político, que derivan que una línea de análisis histórica, como se puede evidenciar a través de la Sentencia C 006 del año 2002, en la cual la Corte misma, señala el tratamiento diferencial que la legislación le debe dar al trabajador agrario, en cuanto al acceso a la propiedad rural, con la (UAF), el legislador busco evitar que la parcelación de la tierra en minifundios que la hagan improductiva e impedir la concentración de la propiedad, redefinido como el fenómeno del fraccionamiento antieconómico de la propiedad en extensiones menores a las de la medida permitida y de la productividad, es por eso que en la sentencia se declaró exequible el artículo 45 de la Ley 160 de 1994, en el cual se definen expresamente las excepciones para el fraccionamiento de los predios objeto de reforma agraria.

Como se mencionó anteriormente, la línea de protección al trabajador agrario no es un efecto jurídico reciente, a causa de la Sentencia C 006 de 2002, para analizar el caso, la Corte se remite a sus propios fallos, para reconocer el papel de la reforma agraria y del campesinado a través del constitucionalismo, donde se referencia la Sentencia C 021 de 1994 (M.P. Antonio Barrera Carbonell) y la Sentencia C 223 de 1994, eventos en que la Corte Constitucional a través de los cuales se ha resaltado la importancia de la actividad agropecuaria y del campo, como medio para garantizar el ejercicio de los derechos sociales, 
económicos y culturales, también conocidos como "derechos de la segunda generación, cuyo significado esencial lo constituye el reconocimiento de que el hombre debe vivir y desenvolverse dentro de unas condiciones económicas, sociales y culturales acordes con su propia condición, cuyo logro es responsabilidad del Estado". Teniendo en cuenta que estos fallos constitucionales fueron anteriores a la entrada en vigencia de la Ley 160 de 1994 y a la aparición de la figura de las ZRC en la vida jurídica nacional, momento en el que está vigente la Ley 135 de 1961.

Finalmente, para terminar con la relación de algunos de los fallos de la Corte Constitucional, se encuentra la Sentencia T 068 de 1998 M. p. Alejandro Martínez Caballero), en la que a través de una acción de tutela, se exige a una entidad pública, la realización de una actividad, el objetivo fundamental de proteger inmediata y eficaz de los derechos fundamentales que resulten amenazados o vulnerados, debido a la inefectividad institucional.

Por esta razón, las sentencias referida, es la Corte que a través del análisis del caso logra establecer, las obligaciones de las entidades públicas, para así, lograr de los objetivos y fines del Estado, que a su vez, requieren de una función administrativa eficiente que responda a las exigencias sociales planteadas en el modelo del Estado Social de Derecho, de tal manera que concrete la efectividad de los deberes jurídicos mediante la función de sus instituciones.

Pero cuando los postulados anteriores, del principio de efectividad de los derechos, no cumplen con las obligaciones, esto significa que existe un problema estructural de ineficiencia e inoperancia administrativa de forma omisiva, según la sentencia, que de acuerdo a la población a la que se dirija, afectaría los derechos fundamentales reconocidos, lo cual no sólo afecta derechos individuales, sino también afecta a todo el aparato jurisdiccional, lo afecta en la efectividad del cumplimiento oportuno de sus obligaciones. "Un estado de cosas contrario a la Constitución" como explicó por la Sala Plena de la Corte Constitucional.

\subsubsection{Marco Jurídico Internacional}

En efecto y partiendo de la Declaración Universal de Derechos Humanos de 1948 aprobada por la Asamblea General de Las
Naciones Unidas, todos los seres humanos son iguales, tenemos derechos iguales e inalienables, derechos como la propiedad, individual y colectivamente, establecido en el artículo 17, satisfacción de los derechos económicos, sociales y culturales del artículo 22 de esta declaración, así como el derecho al trabajo y otros derechos desarrollados en esta proclamación universal.

Complementariamente se encuentra, los Pactos Internacionales de Derechos Económicos, Sociales y Culturales, de Derechos Civiles y Políticos, aprobados por Colombia mediante la Ley 74 de 1968, cuyo texto describe las condiciones de equidad, igualdad, para el reconocimiento de los derechos desarrollados en los pactos, como lo son, el derecho al trabajo, asociación sindical, seguridad social, la familia, alimentación, salud, educación y participación política entre otros, todos desarrollados por el constituyente en 1991.

Es ahí, donde tiene especial importancia y conexión los Derechos Económicos sociales y culturales de la población campesina en Colombia con el desarrollo de figuras alternativas como las Zonas de Reserva Campesina, debido a su enfoque programático hacia el desarrollo equitativo e igualitario en la efectividad de los derechos sociales, económicos y culturales de los campesinos, desarrollados en el artículo 80 de la Ley 160 de 1994, como en el marco legal se definió.

Por otro lado, es posible observar avances significativos frente a la búsqueda de instrumentos internacionales de protección del campesinado y su actividad se encuentra la Declaración Internacional de los Derechos Campesinos y Campesinas, aprobada por el Consejo de Derechos Humanos ONU (2013), establece los derechos de los campesinos y de otras personas que trabajan en las zonas rurales, aprobado por parte del Comité Consultivo de los Derechos Humanos de las Naciones Unidas. En él se puede apreciar la propuesta de los Congresos mundiales de la Vía Campesina en el cual dirigentes convergieron en Ginebra y que contiene los propósitos de lograr que este instrumento jurídico internacional se haga una realidad en el marco del Derecho Internacional de los Derechos Humanos, por tanto tiene el valor de haber sido elaborado por las bases campesinas de organizaciones de muchos países del mundo, entre las que se cuenta 
a la Asociación Nacional de Zonas de Reserva Campesina en Colombia (ANZORC).

De tal modo que reconoce a los campesinos, mujeres y hombres, como sujeto de derechos, paso esencial hacia el reconocimiento, la promoción y la protección de los derechos de los campesinos a nivel internacional, en el cual también resalta su papel en el desarrollo de actividades agropecuarias como parte el derecho fundamental a la protección contra el hambre de la humanidad, mediante el perfeccionamiento o la reforma de los regímenes agrarios.

De la misma forma, a nivel internacional, se ha desarrollado la Ley Marco sobre el derecho a la Alimentación, Seguridad y Soberanía Alimentaria y nutricional de la población, para el disfrute de una vida sana y activa, en la cual se reconoce como un derecho humano formalmente al derechos a la alimentación, conexa con la vida conforme lo establece su artículo 25: toda persona tiene derecho a un nivel de vida adecuado, que le asegure, al igual que a su familia, la salud y el bienestar, en especial a la alimentación. Esto con carácter vinculante en adoptar las medidas necesarias para lograr progresivamente la plena efectividad de los derechos y evitar el hambre.

\section{CONCLUSIONES}

\section{Consideraciones históricas y sociales}

Partiendo de la idea, de cómo el Estado colombiano, realizo una serie expediciones legislativas, cada una para su momento, que a su vez generaron unos efectos jurídicos y sociales en su aplicación y ejercicio, como se puede ver en el marco teórico, tuvieron resultados sociales negativos, que desembocaron e incentivaron en violencia social, política y detrimento económico de la población, en algunas regiones del país, especialmente en zonas de carácter rural, dentro de ellas el Sumapaz.

La raíz de esos conflictos, se ha caracterizado por ser disputas de territorio, por ocupación de campo y de las tierras productivas, pues Colombia ha sido históricamente un país con vocación rural y agraria, en el que los factores y medios de producción tienen protagonismo en el modelo económico, contrariado con fenómenos sociales como el desplazamiento forzado, violación de derechos humanos y abandono institucional en la prestación de servicios públicos entre otros, siendo sujeto pasivo la población campesina que es el activo bruto del medio productivo del campo.

Así como, una reforma agraria redistributiva de baldíos no concretada, no sólo por los costos políticos que acarreaba sino también porque nunca se consideró en las distintas políticas agrarias que se formularon, es decir a una política no se le puede pedir ni interpelar por objetivos que nunca han sido establecidos; hecho que permite entender los escasos y marginales intentos redistributivos en las partes integradas del territorio nacional.

De hecho, los procesos de colonización se introdujeron como mecanismo por medio del cual se liberó la tensión existente en el campo, al constituirse en una válvula de escape a las contradicciones que se generaron en las regiones donde la frontera se había cerrado hace poco o estaba en proceso de cerrarse tal como evidencia con la región del Sumapaz.

El hecho que, no hubo propósito político para modificar la estructura agraria, para facilitar y promover el ascenso social y político de los pobladores rurales. Esto vinculado a la infectividad e ineficacia institucional del sector rural para afrontar las necesidades del pueblo y de los fenómenos sociales históricos.

De esta manera, el planteamiento no solo como una figura para el ordenamiento territorial se esgrime bajo las propuestas sociales de las organizaciones campesinas, sino que se plantea que las ZRC, son escenarios de cambio, social, económico, ambiental y político, para los beneficiados bajo la figura, de manera directa, pues se propende por la mejora de las condiciones de vida y la búsqueda de oportunidades de desarrollo local. Lo que responde a los intereses generales constitucionales y legales establecidos.

Entonces, de acuerdo a lo anterior se puede inferir que la figura de Zonas de Reserva Campesina, fue producto de una lucha campesina permanente a través de movilizaciones, organizaciones y participación, donde el campesino entro en el juego participativo y emancipatorio de condiciones sociales justas, a través de la organización, 
preparación y fortalecimiento político de las comunidades rurales.

Es así que, la región del Sumapaz ha realizado un importante aporte a la construcción la lucha política campesina, mediante las movilizaciones y una postura política indeleble, las organizaciones campesinas del Sumapaz, demostrando la afirmación fiel al objetivo social, presentado a lo largo de los proceso históricos y caracterizado mediante una observación etnográfica, como método y técnica, para describir que a lo largo de las demandas sociales de dignidad, igualdad, oportunidad, y al reconocimiento de esto, con la constitución de una ZRC.

Es pues el campesino empoderado como sujeto político involucrado, que encontró respuesta a las situaciones que lo exponen a condiciones en las cuales se vea afectado, y a su vez, encontró los mecanismos democráticos y cívicos para contrarrestar estas medidas y sus efectos, algunos de los cuales se puede evidenciar en el proceso histórico del agro en Colombia. El cual ha retomado la iniciativa civil, planteando la necesidad de que los movimientos populares puedan ser protagonistas en la construcción de una paz y justicia social, que garantice entre otras demandas legítimas de las formas de vida comunitaria dignas en los ámbitos rurales.

La retoma de manera articula y organizativa, es el ejemplo del Sumapaz, una zona de contrastes, riqueza natural abundante, riqueza poblacional, trascendencia política, procesos sociales de movilización y fortalecimiento de corrientes generacionales precedentes como una construcción histórica de resistencia popular, una serie de iniciativas locales, una serie de oportunidades comunitarias y un solo objetivo, el reconocimiento de la dignidad del campesino al mejorar las condiciones de vida.

Conforme a los fenómenos sociales a nivel rural, la falta de gestión e inversión pública, para los sectores productivos de pequeños y medianos propietarios y poseedores de la tierra, se generó un fenómeno político y jurídico, donde le campesino se volvió un sujeto estigmatizado y relegado a un plano, acompañado de la figura de las ZRC, por políticas de exclusión social y agraria, donde la atención se lleva a discusiones de interés político y económico, y no sobre las calidades y cualidades de vida de los personas de zonas rurales. Pero fundamentalmente en aquella época, de regiones afligidas por el conflicto armado, la violencia por varios factores sociopolíticos, entre ellos la siembra de cultivos de uso ilícito, la fuerza pública represiva, se manifiesta la movilización social organizada alcanzado los objetivos, ejemplo de esto es las movilizaciones sociales campesinas de los años 90 , resultado de esto es la implementación de las zonas de reserva campesina dentro del ordenamiento jurídico.

Con la aparición del nuevo modelo del estado social de derecho, se abrió este escenario de cambio, pues el reconocimiento de la diversidad étnica y cultural de la nación, viendo al campesinado como elemento importante en la construcción de Estado. Es así que, este reconocimiento conllevaría a la elevación formal de las condiciones sociales del campesino como persona, y como grupo social, para darle el reconocimiento como sujeto de derechos y también de obligaciones especiales, como lo son los derechos fundamentales, y los derechos para el trabajador agrario.

En síntesis, conforme a los puntos anteriores, las ZRC, se presenta como in mecanismo efectivo, para las comunidades campesinas de base, como población vulnerable que, mediante la figura articulan sus iniciativas, necesidades $\mathrm{y}$ posibilidades y las dirigen hacia objetivos comunes, donde se marca el interés colectivo y general de buscar alternativas de desarrollo a través de la participación y democratización.

Es a través, de la búsqueda y constitución de las ZRC es que, las organizaciones comunitarias fortalecen los procesos de evolución y crecimiento social y cultural, desde las bases populares, al consolidar la identidad colectiva e individual del campesino, su vinculación y relación con la tierra, pues mediante los procesos de regularización y formalización de la propiedad, soberanía alimentaria e inversión para proyectos productivos agro sostenibles, se conecta con el propósito y misión

A su vez, al campesino se surge un estatus jurídico y político de interacción con las instituciones, pues al movilizarse y demandar legítimamente el libre ejercicio de sus derechos, interactúa también con el sistema jurídico, como sujeto político y como sujeto de derechos. La movilización social y la dinámica campesina, toma 
importancia, pues la efectividad y consecución de objetivos organizativos reside en la participación ciudadana y representación política, porque es la movilización social un esfuerzo común, con base en experiencias colectivas a causa de las desigualdades sociales del campo en Colombia, como lo es la lucha por la tierra.

\section{Consideraciones jurídicas}

En lo desarrollado en el marco jurídico, se puede ver el estado actual de la normatividad y sus avances, una visión sistemática de factores, donde el beneficiario es el protagonista y el medio es la norma, pero cuando el medio no llega y no cumple sus propósitos referentes a su beneficiario ¿qué sucede?

Respecto al marco jurídico, las disposiciones constitucionales se expresan de forma coherente, entre el precepto normativo y los fines estatales, al reconocer al deber de garantizar la efectividad de los principios, derechos y deberes consagrados en la carta política del año 91, estableciendo una prestación oportuna y eficaz de los derechos, en la prestación del servicio público los derechos Económicos, Sociales y Culturales - DESC de los campesinos.

Este es el punto de partida, para el análisis de la efectividad de los derechos y de las normas jurídicas, pues como se refleja en la investigación, la legislación colombiana parte con la constitución Política Nacional de 1991, que tuvo nueva connotación respecto al reconocimiento de los derechos fundamentales de los nacionales, protección y garantías para su ejercicio, y de la visión del campesino como sujeto de derechos dentro del ordenamiento jurídico y político del país y establece el principio de efectividad y eficacia con la única pretensión de garantizar la validez y efectividad de la norma constitucional tenga operancia hacía de los derechos Económicos, Sociales y Culturales DESC.

La importancia constitucional de las normas relativas a los derechos de los campesinos, de los trabajadores agrarios, a las actividades agrícolas y a los aspectos ambientales, radican en la supremacía y valor jerárquico que posee la Constitución política de Colombia dentro del sistema jurídico, como norma de normas, tal cual lo dice el artículo 4 de la CPN. A esto se suma, la intención de garantizar la armonía del sistema normativo y de los medios jurídicos para satisfacer las condiciones mínimas de efectividad de los derechos sociales, económicos y culturales de los campesinos, es la misma Ley 160 de 1994 que plantea a las ZRC como instrumento para aplicabilidad de la los principios constitucionales.

Partiendo de las definiciones expuestas, las ZRC son instrumentos para desarrollar una política orientada a las comunidades y territorios, política que tiene relaciones y efectos con área diversas de las prioridades y actividades públicas, por lo que el Estado debe tomar la decisión política de darles un fundamento legal sólido, garantías jurídicas de permanencia y aplicabilidad real.

Adicionalmente revisando el recorrido de la jurisprudencia, La Corte Constitucional plantea que "el campo no puede ser reconocido únicamente como un área geográfica ordenada por regímenes distintos de autoridades nacionales o locales, por el acceso igualitario a la propiedad, en planes de ordenamiento territorial y por tierras baldías que administra el Estado. Ofreciendo su compresión como un "bien jurídico protegido" para garantizar derechos subjetivos e individuales, derechos sociales y colectivos, así como la seguridad jurídica pero además, es herramienta básica de la supervivencia y el progreso personal, familiar y social." Las reflexiones van hacia a afuera del proceso

Por el contrario, del actual marco normativo interno e internacional, es evidente que aún se presentan dificultades y limitaciones el acceso efectivo de la tierra, en favor de los campesinos, para la constitución de las Zonas de Reserva Campesina que agrava las condiciones de vulnerabilidad de la población rural, la no protección a sus derechos económicos, sociales y culturales, al disminuir la cantidad de terrenos disponibles para delimitación y constitución de Zonas de Reserva Campesina y adjudicación de tierras para sus beneficiarios.

Puede deberse al poco reconocimiento gubernamental de la figura ZRC y a la vinculación por parte del Gobierno Nacional en la concertación con comunidades. Para al otorgamiento de subsidios, incentivos y estímulos a favor de la población campesina en materia de créditos agropecuarios, capitalización rural, adecuación de tierras, desarrollo de proyectos alternativos, modernización y el acceso ágil y eficaz a los servicios públicos rurales. 
Con el fin de responder a la pregunta problema de investigación referente a si, el proceso de constitución de una ZRC es o no efectivo, se tiene las gestiones jurídico administrativas de las entidades que ha existido relacionadas al proceso de constitución de una ZRC.

\section{Consideraciones Institucionales}

La secuencia institucional, iniciada por el INCORA, sucedida por el INCODER, muestra demoras e incumplimiento a los plazos legales para tramitar las solicitudes de constitución de ZRC que actualmente se encuentran en proceso de constitución y/o trámite. Se evidencia un rezago importante en la gestión institucional ya al momento de realizarse las modificaciones institucionales entre la liquidación del INCODER a finales de 2015 y el inicio de actividades de las ANT, se amplían los tiempos de suspensión de trámites y subrogación la competencia de la nueva entidad, rompiendo la continuidad de los procesos, pues las actividades debía seguirse ejecutando, de una entidad a la otra, pero la ruptura del asunto se presenta adicional a las demoras y dilaciones anteriores, entre las demoras administrativas de la entrada en función plena de la nueva Agencia, es decir entre los meses de Diciembre, momento que se enuncia la supresión de la primera y la creación de la segunda.

Como es el caso del Sumapaz, no han dado culminación del trámite de la nueva ZRC, agravando a un más la situación, institucionalmente, no se ha logrado constituir ninguna zona desde la creación del INCODER hasta su liquidación, estando pendiente procedimientos como la convocatoria a celebrar audiencias públicas y presentación de proyectos de Acuerdo, en muchas de las solicitudes.

Desde principio de efectividad de los derechos y de las normas jurídicas, estaríamos frente al problema jurídico de la legitimidad del Estado Social de Derecho en su capacidad para resolver las dificultades sociales desde la perspectiva de la justicia social y el derecho, bajo el postulado de la ineficiencia administrativa para atender efectivamente el proceso de constitución de las zonas de reserva campesina, marcando lo que la corte denomino estado de cosas inconstitucional.

Es por el estado de inefectividad institucional donde se advierte sobre la necesidad de tomar medidas encaminadas a superar la transgresión de las normas superiores. Dirigidas a favorecer la efectividad a los derechos y al cumplimiento de los fines y objetivos del Estado Social de Derecho. Frente a estas necesidades se plantea cambio y reformas del sector rural, se divisan posibilidades mayores al realizar proyecciones sobre escenarios del posconflicto como elemento crucial de acción institucional, una acción programada articulada para que de manera efectiva se logre mejorar la calidad de vida del campesinado colombiano. 


\section{BIBLIOGRAFÍA}

\section{Referencias teóricas}

- Alcaldía Mayor de Bogotá. Secretaria de Hacienda (2004) Recorriendo Sumapaz, Diagnostico físico y socioeconómico de las localidades de Bogotá D.C. Asociación Editorial Buena Semilla. Bogotá D.C.

- Albán A. (s.f) Reforma Y Contrarreforma Agraria En Colombia. Recuperado de http://www.economiainstitucional.com/ pdf/no24/aalban24.pdf

- Arango M. (1986). Logros y perspectivas de la reforma agraria en Colombia. Lecturas de Economía, (21), pp, 169 196. Recuperado de https://dialnet.unirioja.es/servlet/ articulo?codigo $=4834028$.

- Arango M. (1987). Esquemas de políticas agrarias en Colombia. Lecturas de Economía, (23). Pp. 197 220. Recuperado de https://dialnet.unirioja.es/servlet/ articulo?codigo $=4833854$

- Archila, M (2005). Idas y venidas, vueltas y revueltas: protestas sociales en Colombia, 1958 1990.Instituto Colombiano de Antropología e Historia y Centro de Investigación y Educación Popular. Bogotá, Colombia

- Asociación Nacional De Zonas de Reserva Campesina ANZORC (2011). Cartilla pedagógica de las Zonas de Reserva Campesina en Colombia.

- Balcazar, A; López, N; Orozco, M L.; Vega, M. (2001): Alcances y Lecciones de su experiencia en reforma agraria. ONU CEPAL, Red de Desarrollo Agrario. http:// www.eclac.cl. Colombia Bogotá D.C.

- Barrera Becerra, Jorge Enrique, (2003) El Derecho A La Tierra y Las Zonas de Reserva Campesina. DIXI, Centro de Investigaciones Socio Jurídicas C.I.S, Facultad de Derecho, Universidad Cooperativa de Colombia. Bucaramanga. 2003.

- Bobbio N. (1990): Teoría General del Derecho (Debate, Madrid).

- Cadavid M. (2014). La organización campesina y su lucha por la democratización del territorio: un modelo socio territorial de redistribución de la vida y el poder. Tesis de grado Maestra En Estudios Políticos. Pontificia universidad javeriana facultad de ciencias políticas y relaciones internacionales, maestría en estudios políticos Bogotá D.C.

- Céspedes J.(2010) los derechos económicos, sociales y culturales en Colombia (DESC). Un modelo por cumplir. Tesis de grado para administrador Público. Escuela Superior de Administración Pública ESAP. Facultad de pregrado, Programa en ciencias políticas y administrativas Bogotá, D.C.

- Fajardo D. (2002). Tierra, poder político y reformas agraria y rural. Bogotá D.C, Colombia, Instituto Latinoamericano de Servicios Legales Alternativos ILSA.

- Fajardo, D (2008). El campo las políticas agrarias y los conflictos sociales en Colombia. Copia mimeografiada. Publicado posteriormente en Palou Juan Carlos, Aproximación a la cuestión agraria: elementos para una reforma institucional. Fundación Ideas para la Paz, Bogotá.

- Fajardo, Darío y Mondragon Héctor. Moreno Oscar. (1997) Colonización y Estrategias de Desarrollo. Bogotá D.C: Instituto Interamericano de Cooperación Para la, Agricultura.

- Fajardo, Darío. (1998) Colombia Tierra y Paz. Zonas de Reserva Campesina Antecedentes y Contenido. Bogotá D.C.

- Fals Borda, O (1982). Historia de la cuestión agraria en Colombia. Carlos Valencia Editores. Bogotá.

- Gilhodés, P (1985). La Violencia Colombia: bandolerismo y guerra social, en Once ensayos sobre la violencia. Fondo Editorial CEREC: Centro Gaitán. Bogotá.

- González F. (2010). Clientelismo y presencia diferenciada del Estado en un contexto de conflicto armado. Una mirada de largo 
plazo sobre la democracia en Colombia. https://colombiainternacional.uniandes. edu.co/datos/pdf/descargar.php?f=./data/ Col_Int_No.58/05_Rev_58.pdf.

- Gonzalez Posso, Darío. (2003) Zonas de Reserva Campesina. ¿Alternativas para el control comunitario del territorio? Bogotá; Revista Semillas.

- González, F; Vásquez, T; Quiroga, D; Barrera, V y Aponte, A (2012). Aproximación a la evolución del conflicto armado colombiano en el espacio y tiempo: Dinámicas territoriales de los actores armados en Colombia. (Inédito).

- Gros, C y Cusminsky, R (1988). Reforma Agraria y proceso de paz en Colombia. En Revista Mexicana de Sociología, Vol. 50, N. 1 enero marzo, pp. 287302.

- Guillen, F (2008). El poder político en Colombia. Alfaguara, Bogotá.

- Gutiérrez, F (2007). ¿Lo que le viento se llevó? Los partidos políticos y la democracia en Colombia. Grupo Editorial Norma, Bogotá.

- Gutiérrez, F y Barón, M (2006). Estado, control territorial y orden político en Colombia. En Nuestra Guerra sin nombre, Francisco Gutiérrez y María Emma Wills (Coord.). IEPRI, Universidad Nacional, Editorial Norma, Bogotá.

- Hurtado, Carolina. (2000) Zonas De Reserva Campesina: ¿Solución Al Conflicto Agrario en Colombia? Universidad Nacional de Colombia. Facultad de Ciencias Económicas, Bogotá D.C.; Monografía para Optar por el Título de Economista.

- Instituto Colombiano de Desarrollo Rural INCODER. (ed.) 2013. "Balance de la gestión para el ordenamiento social y productivo del territorio: 1960 2012" SIDER 1.0. Bogotá D.C. Editorial INCODER

- Instituto Geográfico Agustín Codazzi (IGAC). Atlas de la Distribución de la Propiedad Rural en Colombia, Bogotá D.C. Imprenta Nacional de Colombia. Recuperado en http://www.igac.gov.co/wps/wcm/conn ect/8beae7804dc8d75abb1efb36b3989 8f6/1_notas_sobre_la_evolucion_historica_ con_cubierta_1.pdf?MOD=AJPERES

- Jaramillo C. (2002). Crisis y transformación de la agricultura colombiana, 19902000. Bogotá D.C. Banco de la República.

- Jaramillo, J; Mora, L; Cubides, F (1989). Colonización, coca y guerrilla. Alianza editorial, Bogotá.

- Londoño. R (2011) Juan de la Cruz Varela. Sociedad y política en la región del Sumapaz (1902 1984), Universidad Nacional, Bogotá.

- Machado A, Vásquez R, Núñez L (2005). La academia y el sector rural N. 5. Universidad Nacional de Colombia, Centro de Investigaciones para el Desarrollo (CID). Bogotá, recuperado de http:// www.cid.unal.edu.co/files/publications/ CID200511maacse.pdf

- Machado A. (1994). El Café, de la aparcería al capitalismo, TM Editores. Recuperado de http://www.bdigital.unal.edu. co/22438/1/19053 62353 1 PB.pdf

- Machado, Absalón. (2004) Proyecto Prospectiva de desarrollo rural y agrario para la paz en Colombia. Estado del arte sobre la producción académica en el sector rural 1986 2003. Universidad Nacional De Colombia. Centro de Investigaciones para el desarrollo Colciencias CIID. Bogotá D.C.

- Machin Sosa, Brauilio. (2012) La Revolución Agroecológica. El Movimiento Campesino de la ANAP. Cuba.

- Martínez, Gabriel, (1999) Las Zonas de Reserva Campesina: alcances y perspectivas en el marco de la política de desarrollo agropecuario y rural, A. Machado, R. Suárez, El mercado de tierras en Colombia: ¿una alternativa viable?, Tercer Mundo Editores, Bogotá,

- Molano A. (1987). Selva Adentro. Una historia de la colonización del Guaviare. El Ancora, Bogotá, Colombia: El Ancora.

- Naranjo Mesa, V. (2006) Teoría 
Constitucional e Instituciones Políticas. Editorial Temis Bogotá D.C. 5ta edición

- Palacios, M. (2011) ¿De quién es la tierra? Propiedad, politización y protesta campesina en la década de 1930, Fondo de Cultura económica y Universidad de los Andes.

- Sánchez, G (1985). La violencia y sus efectos en el sistema político, en Once ensayos sobre la violencia, Fondo Editorial CEREC: Centro Gaitán, Bogotá.

- Sánchez, G (1990). La Violencia de Rojas al frente nacional. En Nueva Historia de Colombia. Vol. II, Santafé de Bogotá: Planeta Colombiana 19891990.

- Sánchez, G y Marteens, D (2006). Bandoleros, Gamonales y campesinos el caso de la Violencia en Colombia. El Ancora Editores, Bogotá.

- Tirado A. (1989). Historia política 1946 1986, Nueva Historia de Colombia. Planeta Editorial Bogotá D.C.

- Vásquez, T. Vargas, A. y Restrepo, J. (2011) Una vieja guerra en un nuevo contexto. Odecofi Cinep. Bogotá, editorial Javeriana.

- Zamosc, L (s.f) .Transformaciones agrarias y lauchas campesinas en Colombia: un balance retrospectivo. Universidad de California, San Diego. Recuperado de http://www.magrama.gob.es/ministerio/ pags/Biblioteca/fondo/pdf/7543_5.pdf

\section{Referencias jurisprudenciales}

- Colombia, Corte Constitucional. Sentencia C 035 /2016. 23 de enero de 1996. M.P. Gloria Stella Ortiz Delgado

- Colombia, Corte Constitucional. Sentencia C 644 / 2012. 23 de agosto de 2012. M.P Adriana María Guillen Arango.

- Colombia, Corte Constitucional. Sentencia
C 223. 18 de mayo de 1995. M. P. José Gregorio Hernández.

- Colombia, Corte Constitucional Sentencia C 021/1994. M. P. 27 de enero de 1994. Eduardo Cifuentes Muñoz.

- Colombia, Corte Constitucional. Sentencia C 037/1994. 3 de febrero de 1994. M.P. Vladimiro Naranjo Mesa.

- Colombia, Corte Constitucional. Sentencia T 068/1998. M. P. Alejandro Martínez Caballero.

\section{Referencias Metodológicas}

- Instituto Colombiano para el Fomento De la Educación Superior, ICFES (1996) Serie de Investigación Social, Modulo 6. La Investigación Evaluativa. Bogotá. Instituto Colombiano Para el Fomento de la Educación Superior, ICFES"

- Hernández Sampieri R. Edi 5ta (2010) Metodología de la Investigación. Mc Graw Hill. México.

- Jaramillo, L. J. (1999). Serie Aprender a Investigar. Módulo 1. Ciencia, Tecnología, Sociedad Y Desarrollo. ICFES, Bogotá D.C.

- Martínez, L. A. (2007). La Observación y el Diario de Campo en la definición de un tema de Investigación. Investigación: Experiencias y Herramientas. Recuperado de http://datateca.unad.edu.co/ contenidos/401121/diario_de_campo.pdf en Junio de 2015.

- Sandín Esteban, M. (2003) Investigación Cualitativa en Educación. Fundamentos y Tradiciones. Madrid. Mc Graw and Hill Recuperado de http://www.postgrado. unesr.edu.ve/acontece/es/todosnumeros/ num09/02_05/capitulo_7_de_sandin.pdf

- Sepúlveda, M. Solano, N. (2008) Metodología de la Investigación social y jurídica. Bogotá D. 